\title{
Synthesis, spectroscopic characterization and thermogravimetric analysis of two series of substituted (metallo)tetraphenylporphyrins
}

\author{
Rasha K. Al-Shewiki ${ }^{1}$, Carola Mende ${ }^{1}$, Roy Buschbeck ${ }^{1}$, Pablo F. Siles ${ }^{2,3}$, \\ Oliver G. Schmidt ${ }^{2,3}$, Tobias Rüffer ${ }^{* 1}$ and Heinrich Lang ${ }^{1}$
}

\section{Full Research Paper}

\section{Address:}

${ }^{1}$ Inorganic Chemistry, Institute of Chemistry, Faculty of Natural Sciences, TU Chemnitz, 09107 Chemnitz, Germany, ${ }^{2}$ Material Systems for Nanoelectronics, TU Chemnitz, 09107 Chemnitz, Germany and ${ }^{3}$ Institute for Integrative Nanosciences, IFW Dresden, Helmholtzstrasse 20, 01069 Dresden, Germany

Email:

Tobias Rüffer - tobias.rueffer@chemie.tu-chemnitz.de

* Corresponding author

Keywords:

electrospray ionization mass spectrometry; IR spectroscopy;

metalloporphyrin; porphyrin; thermogravimetry; UV-vis spectroscopy

\begin{abstract}
Subsequent treatment of $\mathrm{H}_{2} \mathrm{TPP}\left(\mathrm{CO}_{2} \mathrm{H}\right)_{4}$ (tetra( $p$-carboxylic acid phenyl)porphyrin, $\mathbf{1}$ ) with an excess of oxalyl chloride and $\mathrm{HNR}_{2}$ afforded $\mathrm{H}_{2} \mathrm{TPP}\left(\mathrm{C}(\mathrm{O}) \mathrm{NR}_{2}\right)_{4}(\mathrm{R}=\mathrm{Me}, \mathbf{2} ; \mathrm{iPr}, \mathbf{3})$ with yields exceeding $80 \%$. The porphyrins $\mathbf{2}$ and $\mathbf{3}$ could be converted to the corresponding metalloporphyrins $\mathrm{MTPP}\left(\mathrm{C}(\mathrm{O}) \mathrm{NR}_{2}\right)_{4}(\mathrm{R}=\mathrm{Me} / \mathrm{iPr}$ for $\mathrm{M}=\mathrm{Zn}(\mathbf{2 a}, \mathbf{3 a})$; $\mathrm{Cu}(\mathbf{2 b}, 3 \mathbf{3 b})$; $\mathrm{Ni}$ (2c, 3c); $\mathrm{Co}$ (2d, 3d)) by the addition of 3 equiv of anhydrous $\mathrm{MCl}_{2}(\mathrm{M}=\mathrm{Zn}, \mathrm{Cu}, \mathrm{Ni}, \mathrm{Co})$ to dimethylformamide solutions of $\mathbf{2}$ and $\mathbf{3}$ at elevated temperatures. Metalloporphyrins 2a-d and 3a-d were obtained in yields exceeding $60 \%$ and have been, as well as $\mathbf{2}$ and $\mathbf{3}$, characterized by elemental analysis, electrospray ionization mass spectrometry (ESIMS) and IR and UV-vis spectroscopy. Porphyrins 2, 2a-d and 3, 3a-d are not suitable for organic molecular beam deposition (OMBD), which is attributed to their comparatively low thermal stability as determined by thermogravimetric analysis (TG) of selected representatives.
\end{abstract}

\section{Introduction}

Over the last decades metalloporphyrins have been studied in great detail as they exhibit a high chemical and thermal stability, are aromatic and possess distinctive electrochemical and photophysical properties [1-4]. For example, access to the first organic spin valves, which were based on tris(8-hydroxyquinolinato)aluminium $\left(\mathrm{Alq}_{3}\right)$ sandwiched between $\mathrm{La}_{2 / 3} \mathrm{Sr}_{1 / 3} \mathrm{MnO}_{3}$ and cobalt electrodes, was reported more than a decade ago [5]. This finding motivated the development of 
further novel devices as, for example, spin-OFETs (organic field effect transistors) [4]. The nature of the molecules integrated into spintronic devices ranges from purely diamagnetic molecules to individual single molecule magnets (SMMs) [4]. Among such molecules metalloporphyrins are very promising in terms of diverse applications [4]. Recently, we reported on the deposition of thin films of porphyrins of the type $\mathrm{H}_{2} \mathrm{TPP}(\mathrm{OH})_{4}$ (tetra(p-hydroxyphenyl)porphyrin) $[6,7]$ and $\mathrm{MTPP}(\mathrm{OMe})_{4} / \mathrm{H}_{2} \mathrm{TPP}(\mathrm{OMe})_{4}$ (tetra( $p$-methoxyphenyl)porphyrin) $(\mathrm{M}=\mathrm{Cu}[8,9]$, $\mathrm{Ni}[9])$, cf. Figure 1 .

The properties of the metalloporphyrins are governed by the (transition) metal ions and the exocyclic moieties on the individual pyrrole fragments and/or on the meso positions. Comparative studies of the accessibility and characterization of metalloporphyrins are scarcely reported in literature [1-3,10-12], which limits, for example, the possibility to select a certain metalloporphyrin with respect to a desired property by a knowledgebased approach. Along with a preliminary work of us, we noticed that "[...] the electrical analysis and the understanding of the underlying transport mechanism become important for future implementation of porphyrin-based (spintronic) devices.[...]" [8]. It was thus desired to have access to metalloporphyrins of which the central metal ion varies on the one hand, while on the other hand these metalloporphyrins should be sterically more demanding to vary the film morphology compared to our original report [8]. In order to support the idea that different central metals as well as sterically more demanding substituents will vary film morphologies one can, for example, inspect the results of the single-crystal crystallographic characterization even of the compounds displayed in Figure 1. It is instructive to notice, that for $\mathrm{ZnTPP}(\mathrm{OMe})_{4}$ [13] the formation of 2D layers is observed in which symmetry-related molecules with planar porphyrin cores interact with each other by, for ex-

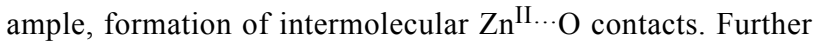
intermolecular interactions refer to those that were described in detail by, for example, Goldberg et al. [14] or by us [15]. In contrast, saddle-shape distorted molecules of $\mathrm{CuTPP}(\mathrm{OMe})_{4}$ are described as interacting via $\mathrm{C}-\mathrm{H} \cdots \pi$ and $\mathrm{C}-\mathrm{H}^{\cdots} \mathrm{O}$ bonds to give a 3D supramolecular motif [16]. Furthermore, if one substitutes the terminal methyl substituents of $\mathrm{H}_{2} \mathrm{TPP}(\mathrm{OMe})_{4}$ (Figure 1) by sterically more demanding substituents as reported for $\mathrm{H}_{2} \mathrm{TPP}(\mathrm{OR})_{4}(\mathrm{OR}=p-(N$ - $n$-butylcarbamoyl $)$ methoxyphenyl $)$ [17] one decreases the density to the materials to $\rho=$ $1.036 \mathrm{~g} / \mathrm{cm}^{3}$ compared to $\rho=1.491 \mathrm{~g} / \mathrm{cm}^{3}$ for $\mathrm{ZnTPP}(\mathrm{OMe})_{4}$ [13] or $\rho=1.398 \mathrm{~g} / \mathrm{cm}^{3}$ for CuTPP(OMe $)_{4}[16]$.

Thus, we report herein on two novel series of (metallo)porphyrins of the type $\mathrm{H}_{2} / \mathrm{MTPP}\left(\mathrm{C}(\mathrm{O}) \mathrm{N}(\mathrm{R})_{2}\right)_{4}(\mathrm{R}=\mathrm{Me}$, with $\mathrm{H}_{2} \mathrm{TPP}\left(\mathrm{C}(\mathrm{O}) \mathrm{NMe}_{2}\right)_{4}(2)$ and $\operatorname{MTPP}\left(\mathrm{C}(\mathrm{O}) \mathrm{N}(\mathrm{iPr})_{2}\right)_{4}(\mathrm{M}=\mathrm{Zn}$ (2a), $\mathrm{Cu}(\mathbf{2 b}), \mathrm{Ni}(\mathbf{2 c}), \mathrm{Co}(\mathbf{2 d}) ; \mathrm{R}=\mathrm{iPr}$, with $\mathrm{H}_{2} \mathrm{TPP}\left(\mathrm{C}(\mathrm{O}) \mathrm{N}(\mathrm{iPr})_{2}\right)_{4}(3)$ and $\operatorname{MTPP}\left(\mathrm{C}(\mathrm{O}) \mathrm{N}(\mathrm{iPr})_{2}\right)_{4}(\mathrm{M}=\mathrm{Zn}$ (3a), $\mathrm{Cu}(\mathbf{3 b}), \mathrm{Ni}(\mathbf{3 c}), \mathrm{Co}(\mathbf{3 d}))$. The aim of this report is not only to describe their synthesis and characterization (ESIMS, FTIR, NMR, UV-vis) but also to study to which extend these new (metallo)porphyrins are suitable to be deposited in form of thin films by OMBD. Therefore, the thermal stabilities derived from TG studies of selected representatives of $\mathbf{2 / 2} \mathbf{a}-\mathbf{d}$ and 3/3a-d in comparison with that of $\mathrm{H}_{2} \mathrm{TPP}(\mathrm{OH})_{4}[6,7]$ will be discussed together with the results of OMBD studies.

\section{Results and Discussion \\ Synthesis}

Porphyrins $\mathbf{2}$ and $\mathbf{3}$ were synthesized as shown in Scheme 1 according to a procedure reported by Gradl et al. [18]. Literatureknown $\mathrm{H}_{2} \mathrm{TPP}\left(\mathrm{CO}_{2} \mathrm{H}\right)_{4}(\mathbf{1})$ was treated first with an excess of oxalyl chloride in dichloromethane in the presence of dimethylformamide. As we used a larger amount of dimethylformamide as indicated in [18], the yields of $\mathbf{2}$ and $\mathbf{3}$ could be increased significantly. This is attributed to the solubility of $\mathbf{1}$ in dimethylformamide. The addition of a large excess of the mild chlorinating agent oxalyl chloride converted 1 to $\mathrm{H}_{2} \mathrm{TPP}(\mathrm{C}(\mathrm{O}) \mathrm{Cl})_{4}$
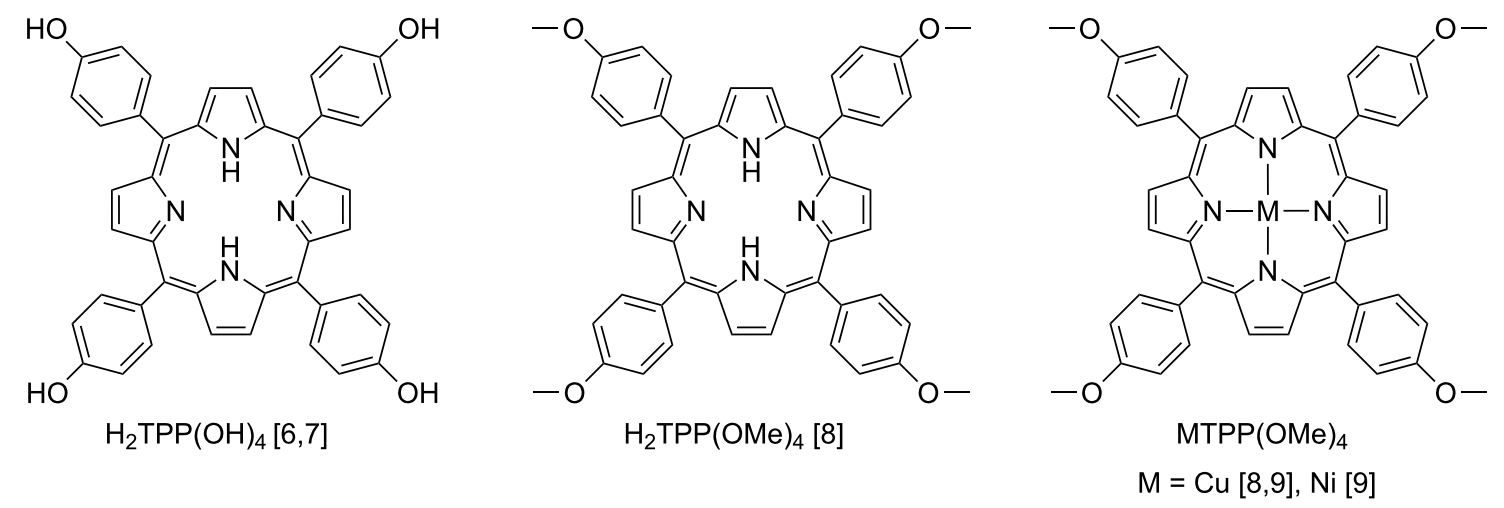

Figure 1: Chemical structures of porphyrins and metalloporphyrins successfully deposited by organic molecular beam deposition. 


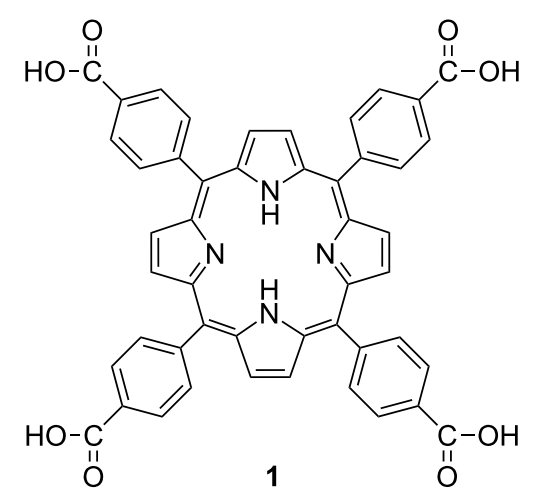

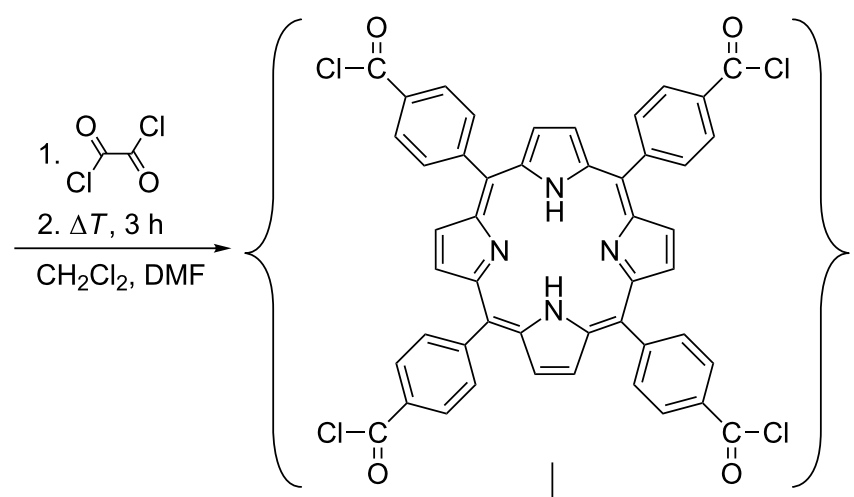

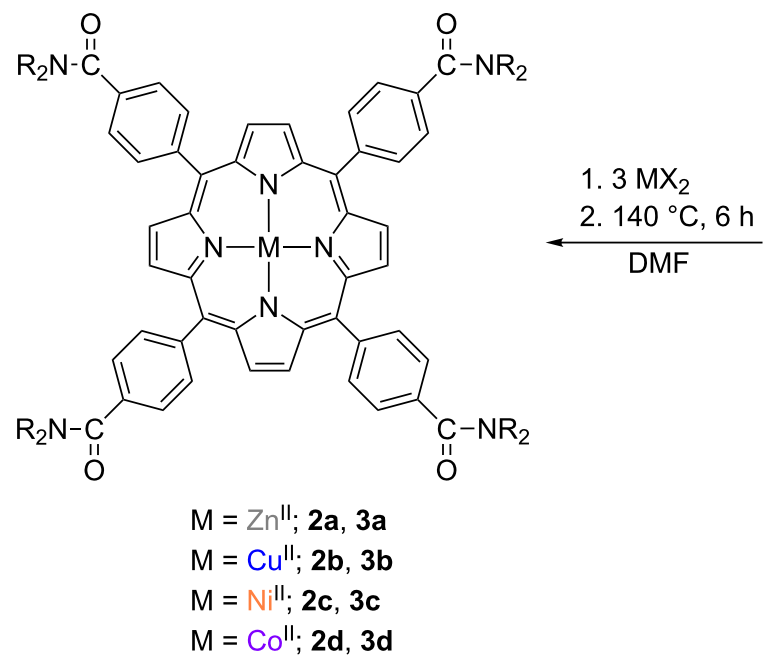

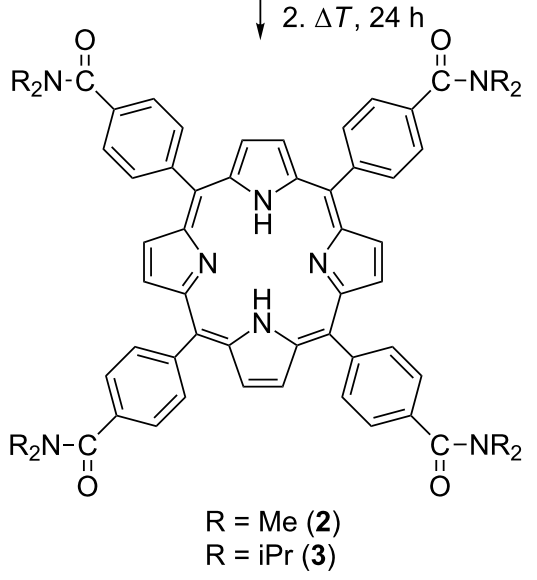

Scheme 1: Synthetic methodology to prepare (metallo)porphyrins 2, 2a-d and 3, 3a-d.

(Scheme 1) which further reacted with the secondary amines $\mathrm{HNMe}_{2}$ and $\mathrm{HN}(\mathrm{iPr})_{2}$ to give $2\left(\mathrm{H}_{2} \mathrm{TPP}\left(\mathrm{C}(\mathrm{O}) \mathrm{NMe}_{2}\right)_{4}\right)$ and $\mathbf{3}$ $\left(\mathrm{H}_{2} \mathrm{TPP}\left(\mathrm{C}(\mathrm{O}) \mathrm{N}(\mathrm{iPr})_{2}\right)_{4}\right)$. The molar excess of oxalyl chloride compared to 1 should be above 25:1, as otherwise 1 cannot be fully converted to $\mathrm{H}_{2} \mathrm{TPP}(\mathrm{C}(\mathrm{O}) \mathrm{Cl})_{4}$. However, the use of thionyl chloride to convert 1 to $\mathrm{H}_{2} \mathrm{TPP}(\mathrm{C}(\mathrm{O}) \mathrm{Cl})_{4}$ is accompanied by chlorination of the $\beta$-pyrrolic positions. After formation of $\mathrm{H}_{2} \mathrm{TPP}(\mathrm{C}(\mathrm{O}) \mathrm{Cl})_{4}$ all volatiles must be removed in vacuum in order to avoid, for example, unwanted reactions upon the addition of $\mathrm{HNMe}_{2}$ and $\mathrm{HN}(\mathrm{iPr})_{2}$. Appropriate work-up, gave $\mathbf{2}$ and 3 in yields exceeding $80 \%$ without any column-chromatographic purification (cf. Experimental section).

The metalation reactions performed in this study correspond to the well-known "dimethylformamide method" $\left(\mathrm{M}^{\mathrm{II}}=\mathrm{Zn}, \mathrm{Cu}\right.$, $\mathrm{Ni}, \mathrm{Co}$ ), cf. Scheme 1 and [19]. In agreement with details reported for the dimethylformamide method, "[...]best results have been obtained with anhydrous metal chlorides[...]" [19], although the reaction temperatures should be kept at $140{ }^{\circ} \mathrm{C}$.
According to [19], complete metalation needs the subsequent addition of an excess of the metal chlorides. Hence, we decided to use initially an excess of the metal chlorides. The metalloporphyrins 2a-d and 3a-d (Scheme 1) have been obtained in yields exceeding $60 \%$. No purification by column chromatography was required although in case of $\mathbf{2 d}, \mathbf{3 a}$ and $\mathbf{3 d}$ the metalloporphyrins were re-precipitated for purification purposes (cf. Experimental section).

The purity of 2, 2a-d and 3, 3a-d was determined by $\mathrm{CHN}$ elemental analysis (EA), although this method has limits. For example, it is difficult to recognize by EA the presence of traces of impurities below ca. $0.5 \%$. Furthermore, the measurement conditions of an EA may influence results as recently demonstrated for a series of octachlorometallophthalocyanines of the type $\mathrm{MPcCl}_{8}\left(\mathrm{M}^{\mathrm{II}}=\mathrm{Cu}, \mathrm{Ni}, \mathrm{Co}, \mathrm{Fe}, \mathrm{Mn}\right)$ [20]. However, for the herein reported porphyrins $\mathbf{2}$ and $\mathbf{3}$ and their corresponding metalloporphyrins $\mathbf{2 a -} \mathbf{d}$ and $\mathbf{3 a}-\mathbf{d}$ the $\mathrm{CHN}$ contents deviate by at most $\pm 0.5 \%$. Since $\mathbf{2} / \mathbf{3}$ and $\mathbf{2 a}-\mathbf{d} / \mathbf{3} \mathbf{a}-\mathbf{d}$ are well soluble in sol- 
vents such as $\mathrm{CH}_{2} \mathrm{Cl}_{2}, \mathrm{CHCl}_{3}, \mathrm{MeCN}$, DMSO, DMF it is possible to follow certain "criteria of purity" established by White, Bachmann and Burnham [21]. Thus, analytical amounts of these (metallo)porphyrins were chromatographed by thin layer chromatography (TLC) on alumina by using $\mathrm{CHCl}_{3} / \mathrm{n}$ hexane mixtures (ratio $1: 1, \mathrm{v} / \mathrm{v}$ ) as eluent, showing that they were formed in high purity.

Furthermore, ${ }^{1} \mathrm{H}$ NMR studies allowed us to monitor the progress of the metalation reactions of $\mathbf{2}$ and $\mathbf{3}$, even for the paramagnetic metalloporphyrins $\mathbf{2 b}, \mathbf{d}$ and $\mathbf{3 b}, \mathbf{d}$. For example, the complete metalations of the free-base porphyrins $\mathbf{2}$ and $\mathbf{3}$ are indicated by the disappearance of their $\mathrm{N}-H^{1} \mathrm{H}$ NMR resonances.

\section{Electrospray ionization mass spectrometry}

High-resolution mass spectrometry (HRMS) studies enable one to verify the successful formation of $\mathbf{2} / \mathbf{3}$ and of $\mathbf{2} \mathbf{a}-\mathbf{d} / \mathbf{3} \mathbf{a}-\mathbf{d}$. The ESIMS measurements in positive-ionization mode were performed under identical conditions, including the use of $\mathrm{MeCN} /$ $\mathrm{CH}_{2} \mathrm{Cl}_{2}$ solutions of the respective (metallo)porphyrin. The ESIMS spectra and the respective isotopic patterns of the ion peaks in form of $[\mathrm{M}]^{+},[\mathrm{M}+\mathrm{H}]^{+},[\mathrm{M}+\mathrm{Na}]^{+}$or $[\mathrm{M}+\mathrm{K}]^{+}$agree to the calculated ones (cf. the ESIMS spectra in Supporting Information File 1). In agreement with Buchler [19] and Budzikiewicz [22] the mass spectrometric measurements served well to identify the type of the incorporated transition metal since the ion peaks of $[\mathrm{M}]^{+}$and/or $[\mathrm{M}+\mathrm{H}]^{+}$are the ones with the highest intensity. The observation of $[\mathrm{M}+\mathrm{Na}]^{+}$as well as $[\mathrm{M}+\mathrm{K}]^{+}$ions and of cations of low $m / z$ values, for example $[393]^{+}$(observed in the ESIMS spectra of $\mathbf{2 c}, \mathbf{d}$ and $\mathbf{3 c}, \mathbf{d}$ ), is due to contaminants that typically appear in such measurements as described in the literature [23,24]. For $\mathbf{2 b}, \mathbf{c}, \mathbf{3}$ and $\mathbf{3 a}-\mathbf{c}$ double charged ion peaks are visible, clearly identifiable by an isotopic peak distance of $m / z=0.5$. This is a common occurrence in ESI measurements when a higher concentration of the analyte is present [23].

\section{IR studies}

Severe difficulties were noticed when measuring $\mathrm{KBr}$ pellets of $\mathbf{2} / \mathbf{3}$ and $\mathbf{2 a}-\mathbf{d} / \mathbf{3} \mathbf{a}-\mathbf{d}$, as described by Alben [25]. These difficiculties are due to, for example, the optical inhomogeneity of the pellets. In order to avoid them, and as suggested by Alben [25], all (metallo)poprhyrins were intensively grinded to a fine flour before further grinding with $\mathrm{KBr}$ was done. It must be emphasized that due to the recommended intense and thus timeconsuming grinding of the pure (polycrystalline) materials the IR spectra reveal the presence of water, likely due to the hygroscopic nature of the compounds and/or of KBr. In Figure 2 (2, 2a-d) and Figure $3(\mathbf{3}, \mathbf{3 a}-\mathbf{d})$ the spectral region between 500 and $1800 \mathrm{~cm}^{-1}$ is displayed. Shaded areas within individual IR spectra displayed in Figure 2 and Figure 3 belong to related absorptions and are numbered. The wavenumbers of these absorptions are summarized in Table 1 for $\mathbf{2} / \mathbf{2} \mathbf{a}-\mathbf{d}$ and $\mathbf{3} / \mathbf{3} \mathbf{a}-\mathbf{d}$. Full IR spectra $(\mathrm{KBr})$ of $\mathbf{2} / \mathbf{3}$ and of $\mathbf{2 a}-\mathbf{d} / \mathbf{3} \mathbf{a}-\mathbf{d}$ are given in Supporting Information File 1. Furthermore, Supporting Information File 1 shows the IR spectra of $\mathbf{2} / \mathbf{3}$ and of $\mathbf{2} \mathbf{a}-\mathbf{d} / \mathbf{3} \mathbf{a}-\mathbf{d}$ as obtained by FTIR measurements with a Nicolet iS10 spectrometer (ATR attachment, ZnSe crystal) for comparison.

For the porphyrins 2 and 3 three different $\mathrm{N}-\mathrm{H}$ vibrations at $3310-3326 \mathrm{~cm}^{-1}, 975-990 \mathrm{~cm}^{-1}$ and $675-700 \mathrm{~cm}^{-1}$ are expected according to [25]. The one observed at $3317 \mathrm{~cm}^{-1}$ for both 2 and 3 (Supporting Information File 1) fits well into the expected range. The vibrations no. 5 and no. 13 for 2 ( 966 and $732 \mathrm{~cm}^{-1}$ ) and 3 (968 and $737 \mathrm{~cm}^{-1}$ ), cf. Figure 2 and Figure 3 and Table 1 , are attributed to the other two $\mathrm{N}-\mathrm{H}$ vibrations. They deviate to some extend from the expected ranges, see above, but the corresponding metalloporphyrins do not show related vibrations (Figure 2 and Figure 3).

The spectral range from 3000 to $2800 \mathrm{~cm}^{-1}$ is governed by $v_{\text {as }}(\mathrm{C}-\mathrm{H})$ and $v_{\mathrm{S}}(\mathrm{C}-\mathrm{H})$ absorptions of the aliphatic substituents $\mathrm{R}$ of the $-\mathrm{C}(\mathrm{O}) \mathrm{NR}_{2}$ groups of both $\mathbf{2} / \mathbf{2} \mathbf{a}-\mathbf{d}$ and $\mathbf{3 / 3} \mathbf{a}-\mathbf{d}$ (Supporting Information File 1). According to [26], $\mathrm{CH}_{3}$ groups can be identified by one $v_{\text {as }}(\mathrm{C}-\mathrm{H})$ absorption at ca. $2950 \mathrm{~cm}^{-1}$ and up to two $v_{\mathrm{s}}(\mathrm{C}-\mathrm{H})$ absorptions at lower spatial frequencies of ca. $2800 \mathrm{~cm}^{-1}$. The number of $\mathrm{CH}_{3}$ groups is eight for $\mathbf{2} / \mathbf{2} \mathbf{a}-\mathbf{d}$, that of $\mathbf{3 / 3} \mathbf{a}-\mathbf{d}$ is 16 . This difference is nicely reflected in the intensities and shapes of the $v_{\mathrm{as}}(\mathrm{C}-\mathrm{H})$ and $v_{\mathrm{s}}(\mathrm{C}-\mathrm{H})$ absorptions. Among 2/2a-d only for 2a and 2c all three possible absorptions could be observed, while further members exhibit only one $v_{\mathrm{s}}(\mathrm{C}-\mathrm{H})$ and the $v_{\mathrm{as}}(\mathrm{C}-\mathrm{H})$ vibration (Supporting Information File 1). For $\mathbf{3 / 3} \mathbf{a}-\mathbf{d}$ the $v_{\mathrm{as}}(\mathrm{C}-\mathrm{H})$ vibration is always the most intensive one at $2970 \pm 1 \mathrm{~cm}^{-1}$, followed by a less intensive first $v_{\mathrm{S}}(\mathrm{C}-\mathrm{H})$ absorption $\left(2932 \pm 1 \mathrm{~cm}^{-1}\right)$ and a third even less intensive $v_{\mathrm{s}}(\mathrm{C}-\mathrm{H})$ band $\left(2874 \pm 4 \mathrm{~cm}^{-1}\right)$. Due to these different spectral features it is possible to differentiate between a type $\mathbf{2} / \mathbf{2} \mathbf{a}-\mathbf{d}$ or $\mathbf{3 / 3} \mathbf{a}-\mathbf{d}$ (metallo)porphyrin.

For the porphyrin cores and the aromatic $\mathrm{C}_{6} \mathrm{H}_{4}$ moieties, respectively, $v(\mathrm{C} \cdots \mathrm{H})$ and $v(\mathrm{C}=\mathrm{H})$ vibrations are expected above $3000 \mathrm{~cm}^{-1}$. However, these vibrations as well as combinations of $\gamma(\mathrm{C} \cdots \mathrm{H})$ vibrations between 2000 and $1600 \mathrm{~cm}^{-1}$, could not be identified unambiguously or were too weak. Likely, this is due to the substitution of the aromatic $\mathrm{C}_{6} \mathrm{H}_{4}$ rings, decreasing the intensities of these vibrations [26].

The presence of $\mathrm{CH}_{3}$ groups in a compound is indicated in the IR spectra in general by one $\delta_{\text {as }}(\mathrm{C}-\mathrm{H})\left(\mathrm{ca} .1465 \mathrm{~cm}^{-1}\right)$ vibration and at least one $\delta_{\mathrm{s}}(\mathrm{C}-\mathrm{H})\left(\mathrm{ca} .1380 \mathrm{~cm}^{-1}\right)$ vibration [26]. Furthermore, a single $\delta_{\mathrm{S}}(\mathrm{C}-\mathrm{H})$ absorption verifies that the $\mathrm{CH}_{3}$ 


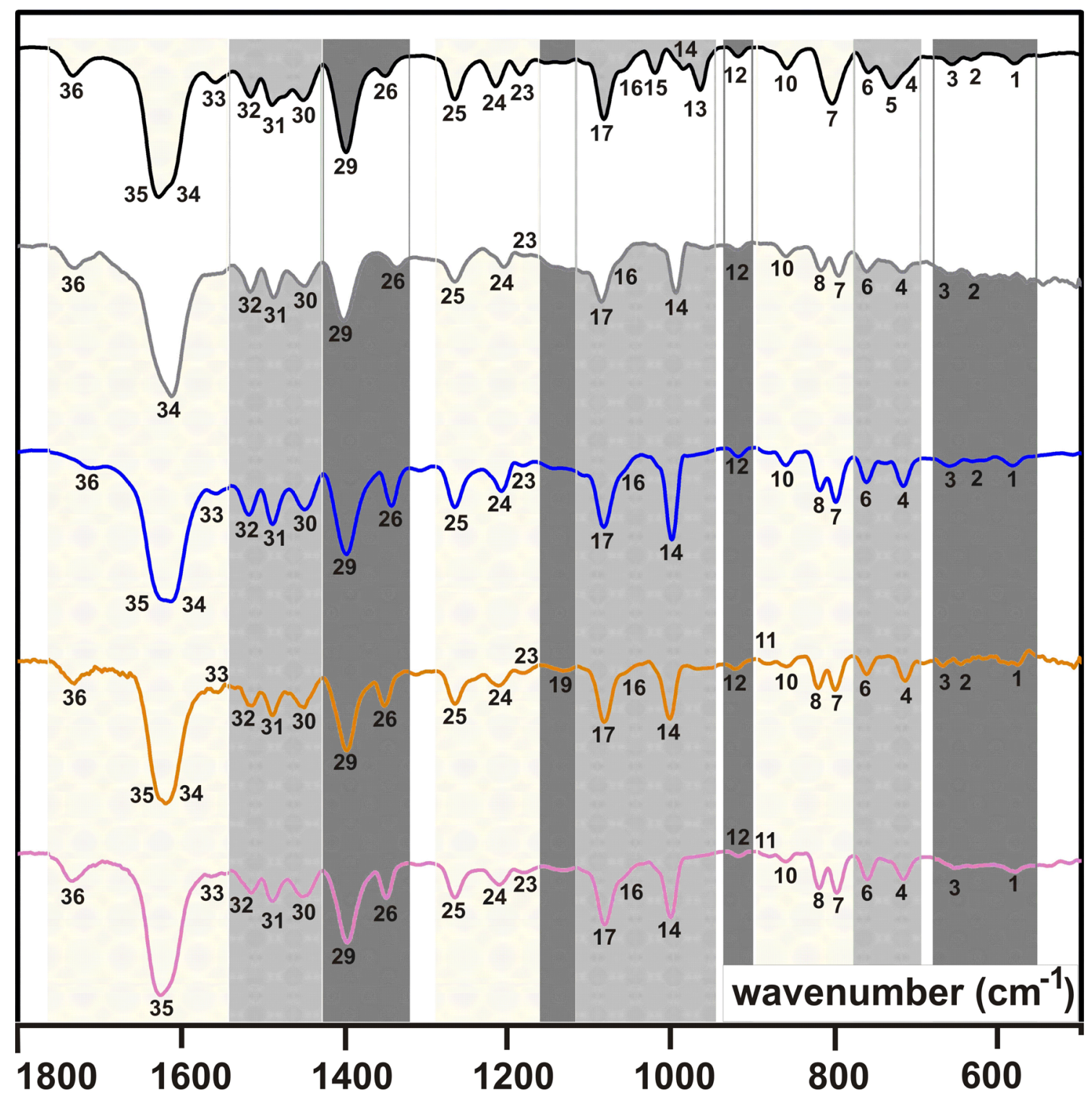

Figure 2: IR spectra $(\mathrm{KBr})$ in the range of $500-1800 \mathrm{~cm}^{-1}$ for $\mathrm{H}_{2} \operatorname{TPP}\left(\mathrm{CONMe}_{2}\right)_{4}(\mathbf{2} \text {, top) and MTPP(CONMe })_{4}\left(\mathrm{M}^{\prime l}=\mathrm{Zn}, \mathbf{2 a}\right.$ (gray); Cu, 2b (blue); Ni, 2c (orange); Co, 2d (purple)).

group belongs to an aliphatic chain that is not branched, or that the Me group is terminal as in the $-\mathrm{NMe}_{2}$ entities of $\mathbf{2 / 2} \mathbf{a}-\mathbf{d}$. For branched alkyl chains the $\delta_{\mathrm{s}}(\mathrm{C}-\mathrm{H})$ vibration splits into two [26]. Thus, the absorptions no. 30 and no. 26 of $\mathbf{2} / \mathbf{2} \mathbf{a}-\mathbf{d}$ $\left(1450 \pm 2 \mathrm{~cm}^{-1}\right.$ and $\left.1344 \pm 7 \mathrm{~cm}^{-1}\right)$ are attributed to the $\delta_{\text {as }}(\mathrm{C}-\mathrm{H})$ and $\delta_{\mathrm{s}}(\mathrm{C}-\mathrm{H})$ vibrations of the terminal $\mathrm{CH}_{3}$ groups (Figure 2 and Table 1). Due to a larger number of $\mathrm{CH}_{3}$ groups in 3/3a-d compared to $\mathbf{2} / \mathbf{2} \mathbf{a}-\mathbf{d}$ the $v_{\mathrm{as}}(\mathrm{C}-\mathrm{H}), v_{\mathrm{s}}(\mathrm{C}-\mathrm{H}), \delta_{\mathrm{as}}(\mathrm{C}-\mathrm{H})$ and $\delta_{\mathrm{s}}(\mathrm{C}-\mathrm{H})$ absorptions of $\mathbf{3} / \mathbf{3} \mathbf{a}-\mathbf{d}$ are more intensive compared to $\mathbf{2 / 2} \mathbf{a}-\mathbf{d}$. For example, the absorption no. 30 of $\mathbf{3 / 3} \mathbf{a}-\mathbf{d}$ $\left(\delta_{\mathrm{as}}(\mathrm{C}-\mathrm{H}), 1442 \pm 2 \mathrm{~cm}^{-1}\right)$ is significantly more intensive compared to $\mathbf{2} / \mathbf{2} \mathbf{a}-\mathbf{d}$ (Figure 2, Figure 3 and Table 1). As expected, for $\mathbf{3} / \mathbf{3} \mathbf{a}-\mathbf{d}$ two $\delta_{\mathrm{S}}(\mathrm{C}-\mathrm{H})$ vibrations are observed, see no. 28 $\left(1379 \pm 1 \mathrm{~cm}^{-1}\right)$ and no. $27\left(1371 \pm 1 \mathrm{~cm}^{-1}\right)$ in Figure 3 and Table 1 . The presence of iPr groups in $\mathbf{3 / 3} \mathbf{a}-\mathbf{d}$ was recognized further by their skeletal vibrations at $1158 \pm 3 \mathrm{~cm}^{-1}$ (no. 23 ), shouldered at $1136 \pm 2 \mathrm{~cm}^{-1}$ (no. 22) [21], while for $\mathbf{2} / \mathbf{2 a}-\mathbf{d}$ only a weak absorption at $1183 \pm 3 \mathrm{~cm}^{-1}$, denoted as no. 23 , is observed.

For para-substituted $\mathrm{C}_{6} \mathrm{H}_{4}$ aromatic units one $\gamma(\mathrm{C} \cdots \mathrm{H})$ absorption between 800 and $860 \mathrm{~cm}^{-1}$ is expected [27], which is one of absorptions no. 7,8 or 10 of $\mathbf{2} / \mathbf{2} \mathbf{a}-\mathbf{d}$ and $\mathbf{3} / \mathbf{3 a}-\mathbf{d}$, (Figure 2, Figure 3 and Table 1). A more precise assignment is not possible, because $\mathrm{C} \cdots \mathrm{H}$ vibrations of the $\beta$-pyrrolic hydrogens are expected to lead to absorptions at $772-805 \mathrm{~cm}^{-1}$ [27]. 


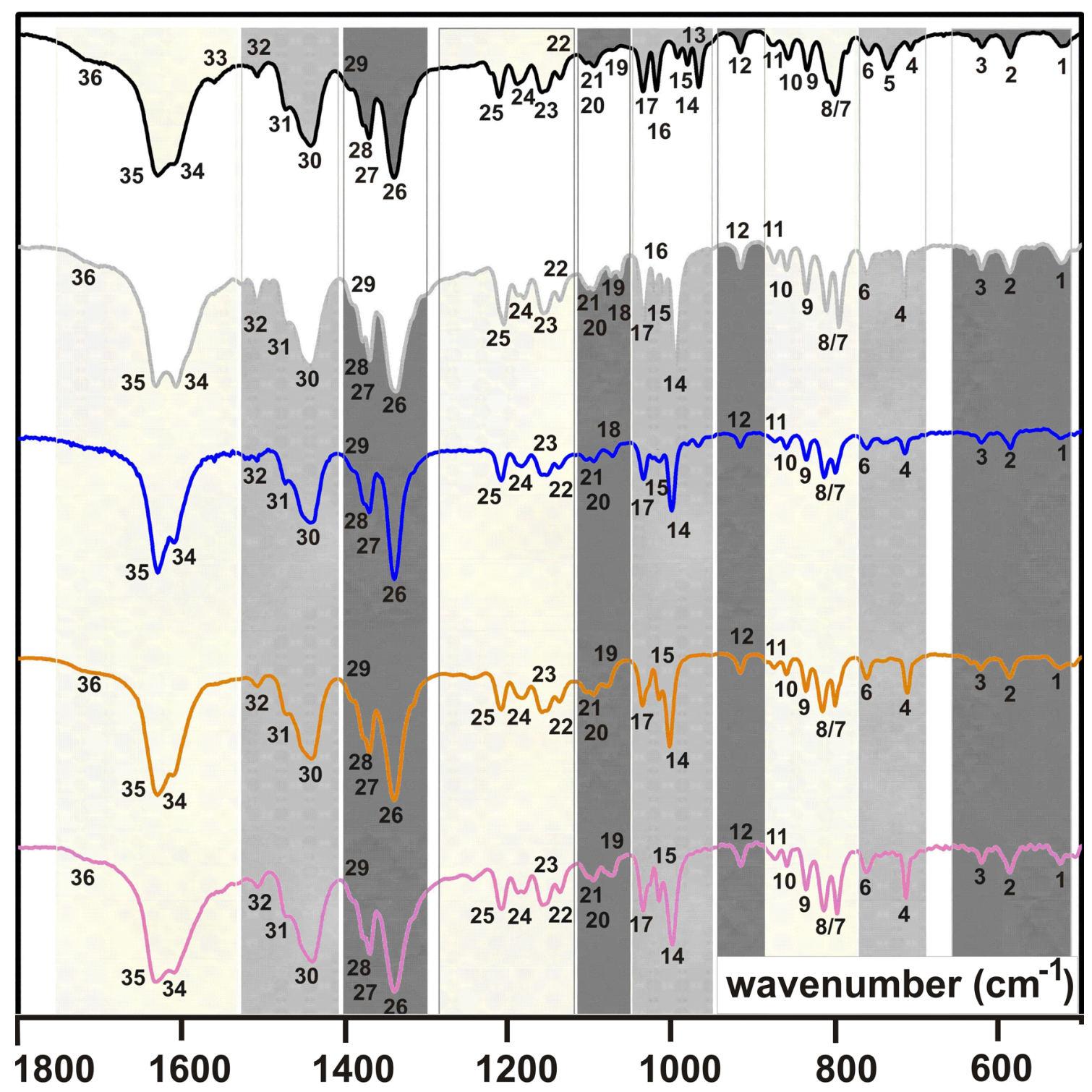

Figure 3: IR spectra $(\mathrm{KBr})$ in the range of $500-1800 \mathrm{~cm}^{-1}$ for $\mathrm{H}_{2} \operatorname{TPP}\left(\mathrm{CON}(\mathrm{PPr})_{2}\right)_{4}(\mathbf{3}$, top $)$ and $\mathrm{MTPP}\left(\mathrm{CON}(\mathrm{iPr})_{2}\right)_{4}\left(\mathrm{M}^{\mathrm{ll}}=\mathrm{Zn}, \mathbf{3 a}\right.$ (gray); $\mathrm{Cu}, \mathbf{3 b}$ (blue); $\mathrm{Ni}, 3 \mathbf{c}$ (orange); Co, 3d (purple)).

Further $\beta$-pyrrolic $\mathrm{C} \cdots \mathrm{H}$ vibrations are expected at $1045-1065 \mathrm{~cm}^{-1}$ [13], and thus no. 17 of $\mathbf{2} / \mathbf{2} \mathbf{a}-\mathbf{d}$ and $\mathbf{3} / \mathbf{3 a}-\mathbf{d}$ can be assigned to them (Figure 2, Figure 3 and Table 1).

The two strongest absorptions of $\mathbf{2} / \mathbf{2} \mathbf{a}-\mathbf{d}$ and $\mathbf{3 / 3} \mathbf{a}-\mathbf{d}$ are due to $v(\mathrm{C} \cdots \mathrm{C})$ vibration of the aromatic moieties and $v(\mathrm{C}=\mathrm{O})$ vibrations of the terminal $-\mathrm{C}(\mathrm{O}) \mathrm{NR}_{2}$ groups [27]. The $v(\mathrm{C} \cdots \mathrm{C})$ vibrations are expected at ca. $1600 \mathrm{~cm}^{-1}$, while the more intense $v(\mathrm{C}=\mathrm{O})$ are observed between 1650 and $1690 \mathrm{~cm}^{-1}$ [27]. This allows for an assignment of no. 35 and no. 34 (Figure 2, Figure 3 and Table 1) to the former and the latter type of vibration, respectively. However, 2/2a-d always exhibit one broad absorption band at ca. $1620 \mathrm{~cm}^{-1}$, which hinders a more precise assignment. For $\mathbf{3 / 3 a - d}$ this situation is different and these two absorption bands occur well resolved. Most likely, that difference can be attributed to the different substitution of the terminal $-\mathrm{C}(\mathrm{O}) \mathrm{NR}_{2}$ groups.

\section{UV-vis studies}

The UV-vis absorption spectra of $\mathbf{2} / \mathbf{2 a}-\mathbf{d}$ and $\mathbf{3} / \mathbf{3 a} \mathbf{a}-\mathbf{d}$ were recorded in $\mathrm{CHCl}_{3}$ solution in the spectral range of $230-700 \mathrm{~nm}$. In order to avoid possible impact of the concentrations on $\lambda_{\mathrm{abs}}$ and $\varepsilon$, which was reported for (metallo)phthalocyanines [28], we performed concentration-dependent UV-vis measurements. According to [28] the nature (cofacial, face-to-face, tilted) and degree (dimer, oligomer, polymer) of mutual interactions 


\begin{tabular}{|c|c|c|c|c|c|c|c|c|c|c|}
\hline \multirow[t]{2}{*}{ no. } & \multicolumn{2}{|c|}{$\mathrm{H}_{2}$} & \multicolumn{2}{|c|}{$\mathrm{Zn}$} & \multicolumn{2}{|c|}{$\mathrm{Cu}$} & \multicolumn{2}{|c|}{$\mathrm{Ni}$} & \multicolumn{2}{|c|}{ Co } \\
\hline & 2 & 3 & $2 a$ & $3 a$ & $2 b$ & $3 b$ & $2 c$ & $3 c$ & $2 d$ & $3 d$ \\
\hline 1 & 582 & 524 & - & 524 & 585 & 526 & 588 & 526 & 581 & 528 \\
\hline 2 & 632 & 587 & 630 & 587 & 634 & 588 & 647 & 588 & 632 & 587 \\
\hline 3 & 658 & 622 & 659 & 622 & 668 & 622 & 668 & 623 & 656 & 623 \\
\hline 4 & 711 & 709 & 718 & 716 & 719 & 715 & 715 & 712 & 718 & 715 \\
\hline 5 & 732 & 737 & - & - & - & - & - & - & - & - \\
\hline 6 & 760 & 760 & 762 & 762 & 761 & 762 & 762 & 762 & 761 & 762 \\
\hline 7 & 804 & 800 & 796 & 797 & 800 & 798 & 800 & 801 & 798 & 800 \\
\hline 8 & - & 810 & 818 & 812 & 819 & 815 & 822 & 816 & 820 & 815 \\
\hline 9 & - & 835 & - & 836 & - & 836 & - & 837 & - & 836 \\
\hline 10 & 860 & 859 & 860 & 860 & 861 & 860 & 860 & 860 & 861 & 861 \\
\hline 11 & - & 878 & - & 875 & - & 875 & 883 & 876 & 882 & 875 \\
\hline 12 & 920 & 917 & 919 & 917 & 918 & 917 & 921 & 917 & 919 & 917 \\
\hline 13 & 966 & 968 & - & - & - & - & - & - & - & - \\
\hline 14 & 987 & 982 & 996 & 996 & 1000 & 1000 & 1003 & 1003 & 1002 & 1001 \\
\hline 15 & 1021 & 994 & - & 1011 & - & 1016 & - & 1016 & - & 1017 \\
\hline 16 & 1059 & 1019 & 1063 & 1021 & 1059 & - & 1055 & - & 1057 & - \\
\hline 17 & 1084 & 1036 & 1086 & 1034 & 1083 & 1035 & 1083 & 1037 & 1082 & 1036 \\
\hline 18 & - & - & - & 1063 & - & 1072 & - & - & - & - \\
\hline 19 & - & 1073 & - & 1076 & - & - & 1030 & 1078 & 1134 & 1072 \\
\hline 20 & - & 1096 & - & 1097 & - & 1095 & - & 1096 & - & 1096 \\
\hline 21 & - & 1106 & - & 1105 & - & 1105 & - & 1106 & - & 1106 \\
\hline 22 & - & 1137 & - & 1138 & - & 1138 & - & 1137 & - & 1138 \\
\hline 23 & 1186 & 1160 & 1180 & 1156 & 1182 & 1158 & 1180 & 1161 & 1180 & 1160 \\
\hline 24 & 1216 & 1190 & 1205 & 1181 & 1206 & 1190 & 1211 & 1183 & 1211 & 1186 \\
\hline 25 & 1266 & 1212 & 1264 & 1206 & 1266 & 1209 & 1265 & 1209 & 1265 & 1209 \\
\hline 26 & 1351 & 1340 & 1337 & 1339 & 1345 & 1340 & 1351 & 1340 & 1349 & 1339 \\
\hline 27 & - & 1370 & - & 1370 & - & 1371 & - & 1370 & - & 1370 \\
\hline 28 & - & 1378 & - & 1378 & - & 1378 & - & 1379 & - & 1379 \\
\hline 29 & 1399 & 1395 & 1400 & 1390 & 1398 & 1391 & 1397 & 1393 & 1397 & 1392 \\
\hline 30 & 1451 & 1442 & 1448 & 1443 & 1450 & 1441 & 1450 & 1441 & 1451 & 1440 \\
\hline 31 & 1489 & 1473 & 1487 & 1472 & 1489 & 1472 & 1489 & 1472 & 1488 & 1473 \\
\hline 32 & 1516 & 1508 & 1515 & 1507 & 1518 & 1506 & 1514 & 1507 & 1514 & 1508 \\
\hline 33 & 1558 & 1561 & - & - & 1560 & - & 1556 & - & 1560 & - \\
\hline 34 & 1609 & 1609 & 1612 & 1607 & 1608 & 1608 & 1619 & 1610 & - & 1609 \\
\hline 35 & 1628 & 1630 & - & 1632 & 1622 & 1632 & 1626 & 1630 & 1625 & 1629 \\
\hline 36 & 1732 & 1701 & 1730 & 1700 & 1711 & - & 1730 & 1710 & 1733 & 1699 \\
\hline
\end{tabular}

${ }^{a}$ cf. Figure 2 and Figure 3.

between (metallo)phthalocyanine molecules might modify their optical absorption spectra [28]. However, the UV-vis studies of $\mathbf{2} / \mathbf{2} \mathbf{a}-\mathbf{d}$ and $\mathbf{3} / \mathbf{3} \mathbf{a}-\mathbf{d}$ with varying concentrations revealed marginal impact on $\lambda_{\text {abs }}(\max . \pm 1 \mathrm{~nm})$ and $\varepsilon(\max . \pm 4 \%)$, see Supporting Information File 1. Larger deviations of $\varepsilon$ are attributed to random errors due to, for example, uncertainties in diluting the sample solutions. The UV-vis spectra of $\mathbf{2} / \mathbf{2} \mathbf{a}-\mathbf{d}$ and $\mathbf{3} / \mathbf{3} \mathbf{a}-\mathbf{d}$ displaying the absorption spectral range from 280-700 nm are shown in Figure 4. For better comparison we select the spectrum of an individual (metallo)porphyrin in which the maximum of the absorption is closest to 1.5 (Supporting Information File 1). Inserts in Figure 4 correspond to the enlarged spectral range of 480-700 $\mathrm{nm}$. Optical absorptions are numbered in relation to the wavelength, $\lambda_{\text {abs }}$ and $\log \varepsilon$ values are summarized in Table 2.

Generally, absorption spectra of free-base porphyrins consist of characteristic absorption bands: The more intense Soret band (or $B$ band) arising from $\mathrm{a}_{1 \mathrm{u}}(\pi) \rightarrow \mathrm{e}_{\mathrm{g}} *(\pi)$ transitions and two $Q$ bands $\left(Q_{\mathrm{x}}(0,0)\right.$ and $Q_{\mathrm{y}}(0,0)$ from $\mathrm{a}_{2 \mathrm{u}}(\pi) \rightarrow \mathrm{e}_{\mathrm{g}} *(\pi)$ transitions 

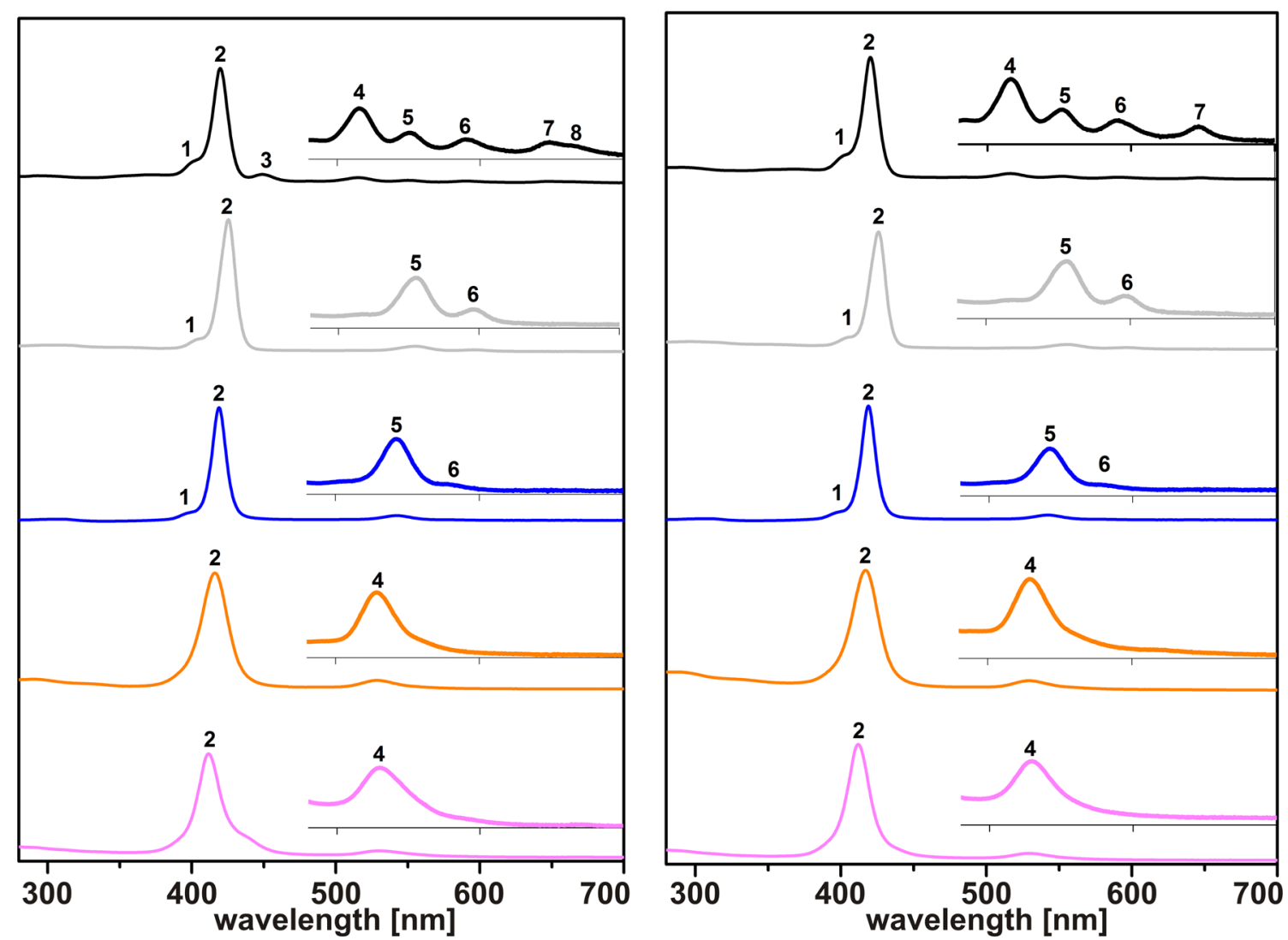

Figure 4: Left: UV-vis spectra $\left(\mathrm{CHCl}_{3}, 280-700 \mathrm{~nm}\right)$ of $\mathrm{H}_{2} \mathrm{TPP}\left(\mathrm{C}(\mathrm{O}) \mathrm{NMe}_{2}\right)_{4}$ (2) and MTPP(C(O)NMe $)_{4}\left(\mathrm{M}^{\prime l}=\mathrm{Zn}, 2 \mathrm{2a}(\mathrm{gray})\right.$; $\mathrm{Cu}, \mathbf{2 b}(\mathrm{blue})$; $\mathrm{Ni}, \mathbf{2 c}$ (orange); Co, 2d (purple)). Right: UV-vis spectra $\left(\mathrm{CHCl}_{3}, 280-700 \mathrm{~nm}\right)$ of $\mathrm{H}_{2} \mathrm{TPP}\left(\mathrm{C}(\mathrm{O}) \mathrm{N}(\mathrm{iPr})_{2}\right)_{4}(3)$ and $\mathrm{MTPP}\left(\mathrm{C}(\mathrm{O}) \mathrm{N}(\mathrm{iPr})_{2}\right)_{4}\left(\mathrm{M}{ }^{\prime \prime}=\mathrm{Zn}, 3 \mathrm{a}(\mathrm{gray})\right.$; $\mathrm{Cu}$, 3b (blue); Ni, 3c (orange); Co, 3d (purple)).

Table 2: Wavelengths of UV-vis absorption bands of $\mathbf{2} / \mathbf{2 a}-\mathbf{d}$ and $\mathbf{3} / \mathbf{3 a}-\mathbf{d}$ in the range of $280-700 \mathrm{~nm}^{\text {a }}$

compound

absorption band no.

\begin{tabular}{|c|c|c|c|c|c|c|c|c|}
\hline \multirow[b]{3}{*}{2} & 1 & 2 & 3 & 4 & 5 & 6 & 7 & 8 \\
\hline & \multicolumn{8}{|c|}{$\lambda_{\mathrm{abs}}(\log \varepsilon)$} \\
\hline & $401(4.95)$ & $420(5.64)$ & $449(4.74)$ & $516(4.35)$ & $551(4.08)$ & $591(3.96)$ & 647 (3.93) & 666 (3.93) \\
\hline 3 & $400(4.80)$ & $421(5.49)$ & - & $517(4.17)$ & 552 (3.91) & $590(3.74)$ & $648(3.58)$ & - \\
\hline $2 a$ & $403(4.55)$ & $426(5.55)$ & - & - & $555(4.19)$ & $596(3.73)$ & - & - \\
\hline $3 a$ & 404 (4.33) & 426 (5.29) & - & - & 556 (3.93) & $597(3.53)$ & - & - \\
\hline $2 b$ & $396(4.44)$ & 419 (5.65) & - & - & $542(4.28)$ & 578 (3.39) & - & - \\
\hline $3 b$ & 397 (4.58) & $419(5.74)$ & - & - & $542(4.37)$ & $579(3.43)$ & - & - \\
\hline $2 c$ & - & $416(5.30)$ & - & $528(4.17)$ & - & - & - & - \\
\hline $3 c$ & - & $417(5.32)$ & - & $530(4.23)$ & - & - & - & - \\
\hline $2 d$ & - & $412(5.24)$ & $442(4.44)$ & $530(4.03)$ & - & - & - & - \\
\hline $3 d$ & - & $412(5.47)$ & - & $529(4.25)$ & - & - & - & - \\
\hline
\end{tabular}

${ }^{a}$ cf. Figure 4 
[29,30]. According to Goutermann the $B(0,0)$ band appears between 380 and $420 \mathrm{~nm}\left(\varepsilon>10^{5} \mathrm{M}^{-1} \cdot \mathrm{cm}^{-1}\right)$ and is accompanied in case of well-resolved spectra by a blue-shifted (ca. $\left.1250 \mathrm{~cm}^{-1}\right) B(1,0)$ band [29,30]. $Q$-band absorptions occur in the spectral region between 500 and $700 \mathrm{~nm}$ $\left(\varepsilon>10^{4} \mathrm{M}^{-1} \cdot \mathrm{cm}^{-1}\right)[29,30]$. The $Q_{\mathrm{x}}(0,0)$ and $Q_{\mathrm{y}}(0,0)$ bands of $D_{2 h}$-symmetric porphyrins, separated by ca. $3000 \mathrm{~cm}^{-1}$, might be observed inclusive a vibronic overtone absorption of each $Q$ band, denoted as $Q_{\mathrm{x}}(1,0)$ and $Q_{\mathrm{y}}(1,0)[29,30]$. For metalloporphyrins adapting $D_{4 h}$-type symmetry, the four $Q$ bands are observed to collapse into two $Q$ bands, in some cases into only one $[19,29]$. The accompanying "[...]Soret band may remain in the usual range or shifted to higher or lower frequency.[...]", according to Buchler [19]. Furthermore, (metallo)porphyrins may show a weak $N$ (ca. $325 \mathrm{~nm}$ ) and $M$ band (ca. $215 \mathrm{~nm}$ ), often with an even weaker $L$ band [29].

As expected, for $\mathbf{2}$ and $\mathbf{3}$ the intensive $B(0,0)$ band appears at ca. $420 \mathrm{~nm}$ (no. 2 in Figure 4, Table 2) and is followed by four significantly weaker $Q$ bands at ca. 516, 551, 591 and $647 \mathrm{~nm}$ (no. 4-7 in Figure 4, Table 2). The separation between absorption no. 4 and no. 6 as well as between no. 5 and no. 7 amounts to, respectively, $2394 \mathrm{~cm}^{-1}$ as well as $2684 \mathrm{~cm}^{-1}$ for $\mathbf{3}$, in good agreement with the expected difference between the $Q_{\mathrm{x}}(0,0)$ and $Q_{\mathrm{y}}(0,0)$ band of free-base porphyrins (see below). The blueshifted shoulder of the $B(0,0)$ band at $401 / 400 \mathrm{~nm}$ (no. 1 in Figure 4, Table 2) corresponds to the $B(1,0)$ band of $\mathbf{2}$ and $\mathbf{3}$, confirmed by blue-shifts of 1128 and $1247 \mathrm{~cm}^{-1}$ (see above). As described earlier, and due to symmetry reasons, for $\mathrm{Zn}^{\mathrm{II}}$ - and $\mathrm{Cu}^{\mathrm{II}}$-containing $\mathbf{2} \mathbf{a} / \mathbf{3} \mathbf{a}$ and $\mathbf{2 b} / \mathbf{3 b}$, two $Q$ bands are observed, while $\mathrm{Ni}^{\mathrm{II}}$ - and $\mathrm{Co}^{\mathrm{II}}$-containing $\mathbf{2 c} / \mathbf{3} \mathbf{c}$ and $\mathbf{2 d} / \mathbf{3 d}$ possess only one $Q$ band (Figure 4). The difference in numbers of the $Q$ bands could be caused by a higher molecular symmetry of $\mathbf{2 c / 3 c}$ or $\mathbf{2 d} / \mathbf{3 d}$ compared to $\mathbf{2 a} / \mathbf{3} \mathbf{a}$ and $\mathbf{2 b} / \mathbf{3 b}$, but is most likely attributable to weak perturbations by the central metal according to Goutermann [29]. A comparison of the $\lambda_{a b s}$ values of both the $B(0,0)$ and the $Q$ band(s) along $\mathbf{2} / \mathbf{2} \mathbf{a}-\mathbf{d}$ and $\mathbf{3} / \mathbf{3} \mathbf{a}-\mathbf{d}$ reveals a red-shift along the series $\mathrm{Co}^{\mathrm{II}}<\mathrm{Ni}^{\mathrm{II}}<\mathrm{Cu}^{\mathrm{II}}<\mathrm{Zn}^{\mathrm{II}}$ (Figure 4 and Table 2). This observation is in agreement with observations summarized by Buchler [19] and Goutermann [29]. The same tendency has been observed more recently [11] and no significant differences of $\lambda_{\text {abs }}$ values have been noticed [12], although the UV-vis spectra were recorded in both cases in $\mathrm{CHCl}_{3}$.

\section{Thermogravimetric studies}

Part of our motivation to synthesize $\mathbf{2} / \mathbf{2} \mathbf{a}-\mathbf{d}$ and $\mathbf{3} / \mathbf{3} \mathbf{a}-\mathbf{d}$ originates from a number of cooperations with our partners in the DFG-supported research unit "Towards Molecular Spintronics" [6-9]. For example, (metallo)porphyrins were synthesized and deposited by OMBD for different kinds of physical thin-film studies [6-9]. In one of these contributions thin films of
$\mathrm{CuTPP}(\mathrm{OMe})_{4}$ (Figure 1) were investigated by current-sensing atomic force microscopy [8]. It was concluded that for the investigation of films with different morphologies and transport properties further (metallo)porphyrins should be studied, as outlined in the Introduction section [6-9].

However, we were not able to deposit thin films of $\mathbf{3}, \mathbf{3 b}$ and $\mathbf{3 d}$ nor of $\mathbf{2 ,} \mathbf{2 c}$ and $\mathbf{2 d}$ by means of OMBD. In more detail: OMBD parameters were initially chosen as reported in [8]. Thus, at $2 \times 10^{-7}$ mbar a deposition rate of $5 \AA /$ min was adjusted. In all investigated cases, deposition rates were not stable and constantly decreased over time. In order to maintain a stable deposition rate, the deposition temperatures were constantly increased from 300 to $350{ }^{\circ} \mathrm{C}$ in a Knudsen cell. After keeping the materials for ca. $20 \mathrm{~min}$ at these high temperatures, it was observed that the deposition rates dropped significantly. From this point onwards, it was not possible to perform any (further) deposition of the materials. In case of $\mathbf{3 b}$ and $\mathbf{3 d}$ the remaining material in the Knudsen cell was subjected to IR measurements (Supporting Information File 1) in comparison with measurements of the starting materials, showing that both metalloporphyrins decomposed during the OMBD studies.

In order to shine more light into the temperature stability we carried out TG studies for $\mathbf{3}, \mathbf{3 b}, \mathbf{3 d}, \mathbf{2}, \mathbf{2 c}$ and $\mathbf{2 d}$. The TG traces are shown in Figure 5 together with the one of $\mathrm{H}_{2} \mathrm{TPP}(\mathrm{OH})_{4}$. In our earlier studies [6,7], $\mathrm{H}_{2} \mathrm{TPP}(\mathrm{OH})_{4}$ could be deposited successfully by applying OMBD parameters analogous the those described above. A comparison especially of the onset temperatures of the decomposition processes reveals that $\mathrm{H}_{2} \mathrm{TPP}(\mathrm{OH})_{4}$ is obviously significantly more thermally stable than the here reported (metallo)porphyrins. Because of this, OMBD of $\mathbf{2} / \mathbf{2} \mathbf{a}-\mathbf{d}$ and $\mathbf{3 / 3} \mathbf{a}-\mathbf{d}$ is not possible and we are recently fabricating thin layers of these compounds by spin-coating [31].

\section{Conclusion}

Two series of metalloporphyrins $\operatorname{MTPP}\left(\mathrm{C}(\mathrm{O}) \mathrm{NR}_{2}\right)_{4}\left(\mathrm{M}=\mathrm{Co}^{\mathrm{II}}\right.$, $\left.\mathrm{Ni}{ }^{\mathrm{II}}, \mathrm{Cu}^{\mathrm{II}}, \mathrm{Zn}^{\mathrm{II}}\right)$ derived out of their free-base species $\mathrm{H}_{2} \mathrm{TPP}\left(\mathrm{C}(\mathrm{O}) \mathrm{NR}_{2}\right)_{4}(\mathrm{R}=\mathrm{Me}(\mathbf{2} / \mathbf{2 a}-\mathbf{d}), i \operatorname{Pr}(\mathbf{3} / \mathbf{3 a}-\mathbf{d}))$ were synthesized and characterized by NMR, IR and UV-vis spectroscopy as well as by ESI mass-spectrometry. The comparison of the obtained analytical results revealed only minor differences in vibrational and optical spectra, both with respect to the varied transition metal ions as well as the terminal organic substituent R. That provides potentially useful insight into the material properties of these porphyrins. It was anticipated that the variation of the central transition metal ions along $\mathbf{2 a - d}$ and $\mathbf{3 a}-\mathbf{d}$ modify to the local transport characteristics of OMBDdeposited thin films of these compounds. In addition, in order to modify thin-film morphologies of successfully OMBD- 

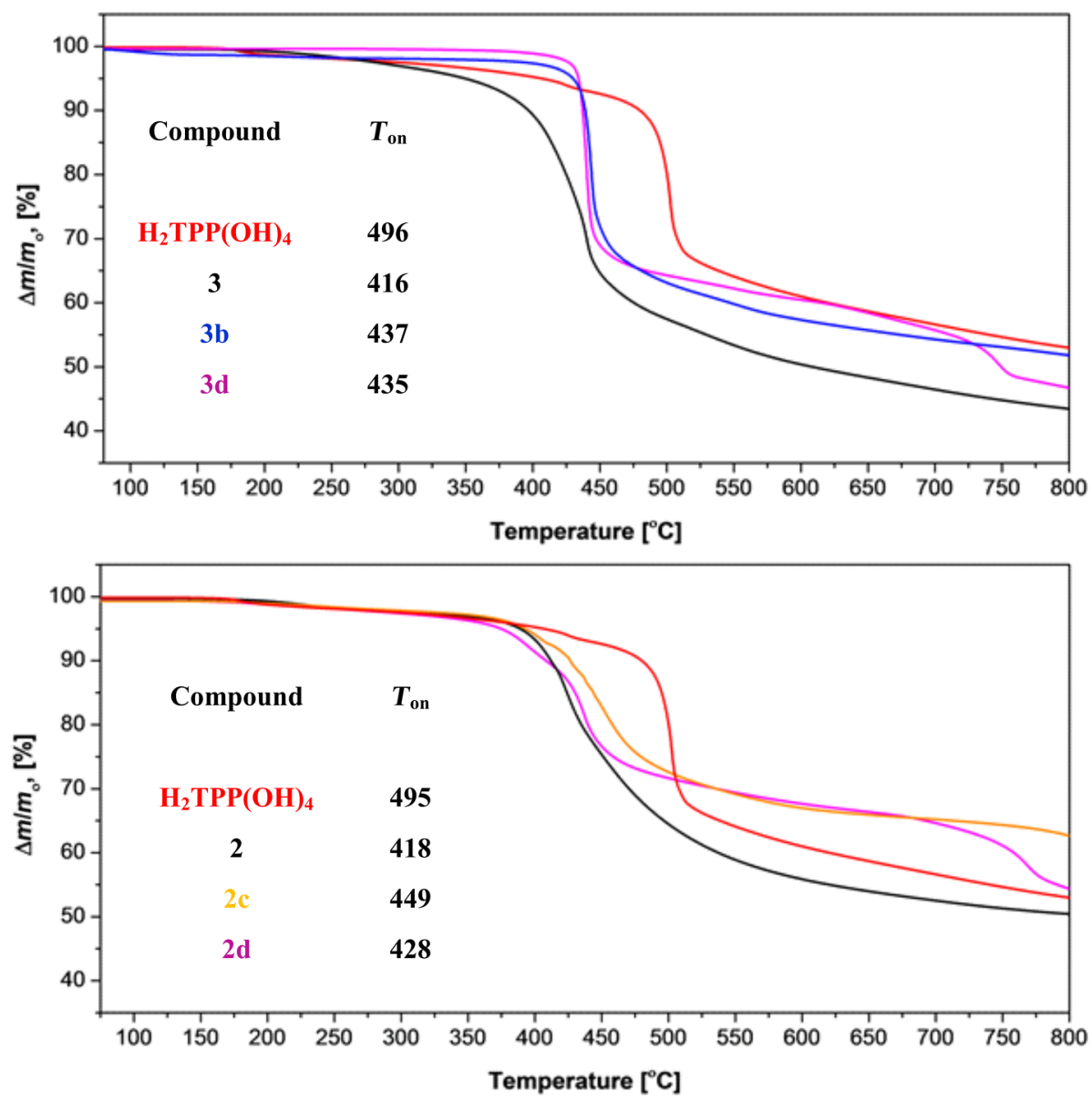

Figure 5: Top: TG traces of 3, 3b and 3d in comparison with $\mathrm{H}_{2} \mathrm{TPP}(\mathrm{OH})_{4}$. Bottom: TG traces of 2, 2c and $\mathbf{2 d}$ in comparison with $\mathrm{H}_{2} \mathrm{TPP}(\mathrm{OH})_{4}$.

deposited $\mathrm{CuTPP}(\mathrm{OMe})_{4} \mathbf{2} / \mathbf{2} \mathbf{a}-\mathbf{d}$ and $\mathbf{3 / 3} \mathbf{a}-\mathbf{d}$ were equipped with sterically more bulky terminal organic groups. Unfortunately, all trials to deposit members of $\mathbf{2} / \mathbf{2} \mathbf{a}-\mathbf{d}$ and $\mathbf{3 / 3} \mathbf{\mathbf { a }}-\mathbf{d}$ by OMBD failed, which is attributed to a significantly lower thermal stability compared to CuTPP $(\mathrm{OMe})_{4}$ [8]. Most likely, the decreased thermal stability of $\mathbf{2} / \mathbf{2} \mathbf{a}-\mathbf{d}$ and $\mathbf{3} / \mathbf{3} \mathbf{a}-\mathbf{d}$ can be attributed to fragmentations of the terminal $-\mathrm{C}(\mathrm{O}) \mathrm{NR}_{2}$ functionalities during heating. Thus, this study shows that the thermal stability of (metallo)porphyrins is subjected to certain limits, and the application of other thin-film depositions techniques is required for $\mathbf{2} / \mathbf{2} \mathbf{a}-\mathbf{d}$ and $\mathbf{3 / 3} \mathbf{a}-\mathbf{d}$.

\section{Experimental}

\section{General conditions}

All chemicals were purchased from commercial sources and were used as received, unless stated otherwise. All reactions were carried out under argon atmosphere using standard Schlenk techniques and vacuum-line manipulations unless stated otherwise. All solvents were distilled prior to use and were purified/dried according to standard procedures [32].

\section{Starting materials}

5,10,15,20-Tetra(4-carboxyphenyl)porphyrin $\left(\mathrm{H}_{2} \mathrm{TPP}(\mathrm{COOH})_{4}\right.$, 1) was synthesized according to [33] and $\mathrm{MCl}_{2} \cdot n \mathrm{H}_{2} \mathrm{O}$ salts $(\mathrm{M}=$ $\mathrm{Zn}^{\mathrm{II}}, \mathrm{Cu}^{\mathrm{II}}, \mathrm{Ni}^{\mathrm{II}}, \mathrm{Co}^{\mathrm{II}}$ ) were dried according to [34].

\section{Instruments}

NMR spectra were recorded at ambient temperature with a Bruker Avance III 500 Ultra Shield Spectrometer $\left({ }^{1} \mathrm{H}\right.$ at $500.300 \mathrm{MHz}$ and ${ }^{13} \mathrm{C}\left\{{ }^{1} \mathrm{H}\right\}$ at $125.813 \mathrm{MHz}$ ) in the Fourier transform mode. Chemical shifts are reported in $\delta(\mathrm{ppm})$ versus $\mathrm{SiMe}_{4}$ with the solvent as the reference signal $\mathrm{CDCl}_{3}:{ }^{1} \mathrm{H} \mathrm{NMR}$, $\delta=7.26$; and ${ }^{13} \mathrm{C}\left\{{ }^{1} \mathrm{H}\right\}$ NMR, $\delta=77.16$. FTIR spectra were recorded in the range of $400-4000 \mathrm{~cm}^{-1}$ with a Perkin-Elmer 1000 FTIR spectrometer as $\mathrm{KBr}$ pellets and in the range of $650-4000 \mathrm{~cm}^{-1}$ with a Thermo Scientific Smart iTR, Nicolet iS10. (The two absorptions at ca. $2360 \mathrm{~cm}^{-1}$, which appear different in intensity from spectra to spectra, are due to $\mathrm{CO}_{2}$.) $\mathrm{C}, \mathrm{H}, \mathrm{N}$ elemental analyses were performed using a Thermo FlashAE 1112 series analyzer. High-resolution mass spectra were recorded with a Bruker micrOTOF QII equipped with an 
Apollo II ESI source. UV-vis absorption spectra were recorded with a Spectronic GENESYS 6 UV-visible spectrophotometer (Thermo Electron Corporation) between 200-800 nm. TG experiments were performed using a Mettler Toledo TGA/DSC1 1600 system with an MX1 balance.

\section{Synthesis of $\mathbf{2}$}

To a suspension of $\mathbf{1}(1.00 \mathrm{~g}, 1.26 \mathrm{mmol})$ in dichloromethane $(140 \mathrm{~mL})$ dimethylformamide $(1 \mathrm{~mL}, 12.9 \mathrm{mmol})$ was added. This reaction mixture was cooled to $0{ }^{\circ} \mathrm{C}$ and oxalyl chloride (3.20 mL, $37.31 \mathrm{mmol}$ ) was added dropwise (within $20 \mathrm{~min}$ ) under continuous stirring. The mixture was stirred at $0{ }^{\circ} \mathrm{C}$ for further 30 min followed by refluxing for $3 \mathrm{~h}$. After all volatiles were removed under reduced pressure the obtained crude product was dissolved in dichloromethane $(30 \mathrm{~mL})$ and a mixture of dimethylamine ( $2 \mathrm{M}$ in tetrahydrofuran, $16 \mathrm{~mL}, 32 \mathrm{mmol}$ ) and triethylamine $(1 \mathrm{~mL}, 7.17 \mathrm{mmol})$ was added dropwise at ambient temperature. The reaction mixture was stirred at this temperature for another $3 \mathrm{~h}$, followed by refluxing for $24 \mathrm{~h}$. Afterward, all volatiles were removed under reduced pressure and hot distilled water $(100 \mathrm{~mL})$ was added to the crude product with continuous stirring for $30 \mathrm{~min}$. The purple precipitate formed was filtered off, washed with hot distilled water $(5 \times 20 \mathrm{~mL})$ and dried at $110{ }^{\circ} \mathrm{C}$ in an oven. Yield: $0.91 \mathrm{~g}(80 \%$ based on 1). Anal. calcd for $\mathrm{C}_{56} \mathrm{H}_{50} \mathrm{~N}_{8} \mathrm{O}_{4}$ (899.05): C, 74.81; $\mathrm{H}$, 5.61; N, 12.46; found: C, 74.3; H, 5.7; N, 12.2; ${ }^{1} \mathrm{H}$ NMR $\left(\mathrm{CDCl}_{3}\right) \delta-2.80\left(\mathrm{~s}, 2 \mathrm{H}, \mathrm{H}^{\mathrm{a}, \mathrm{a}^{\prime}}\right), 3.32\left(\mathrm{~s}, 24 \mathrm{H}, \mathrm{H}^{1,2}\right), 7.84(\mathrm{~d}, 8 \mathrm{H}$, $\left.\mathrm{H}^{6,6^{\prime}}\right), 8.26\left(\mathrm{~d}, 8 \mathrm{H}, \mathrm{H}^{5,5^{\prime}}\right), 8.87\left(\mathrm{~s}, 8 \mathrm{H}, \mathrm{H}^{10,10^{\prime}}\right) ;{ }^{13} \mathrm{C}\left\{{ }^{1} \mathrm{H}\right\} \mathrm{NMR}$ $\left(\mathrm{CDCl}_{3}\right) \delta 35.80\left(\mathrm{C}^{1}\right), 40.15\left(\mathrm{C}^{2}\right), 119.62\left(\mathrm{C}^{8}\right), 125.80\left(\mathrm{C}^{6,6^{\prime}}\right)$, $134.57\left(\mathrm{C}^{7}\right), 135.93\left(\mathrm{C}^{5,5^{\prime}}\right), 143.46\left(\mathrm{C}^{4}\right), 171.80\left(\mathrm{C}^{3}\right)$; HRMS (ESI-TOF, positive mode, $\mathrm{MeCN} / \mathrm{CH}_{2} \mathrm{Cl}_{2}$ ): $\mathrm{m} / z 899.4058$ $[2+\mathrm{H}]^{+}, 937.3515[2+\mathrm{K}]^{+}$; calcd for $\mathrm{C}_{56} \mathrm{H}_{51} \mathrm{~N}_{8} \mathrm{O}_{4} /$ $\mathrm{C}_{56} \mathrm{H}_{50} \mathrm{KN}_{8} \mathrm{O}_{4}([2+\mathrm{H}] /[2+\mathrm{K}])=899.4028 / 937.3587$; IR $\left(\mathrm{KBr}, \mathrm{cm}^{-1}\right)$ v: 3317 (w, N-H); 2929/2897/2866 (m/w/w, C-H); 1629/1609 (s/w, C=O); UV-vis $\left(\mathrm{CHCl}_{3}\right) \lambda_{\text {abs }}[\mathrm{nm}](\log \varepsilon): 401$ (5.24), 420 (5.95), 449 (4.83), 516 (4.64), 551 (4.36), 591 (3.24), 647 (4.17), 666 (4.07); Supporting Information File 1 gives the IR, ${ }^{1} \mathrm{H}$ NMR, ${ }^{13} \mathrm{C}\left\{{ }^{1} \mathrm{H}\right\}$ NMR, UV-vis and ESIMS spectra of $\mathbf{2}$.

Comments: According to Jones and Wilkins [35] for the $-\mathrm{NMe}_{2}$ groups two ${ }^{13} \mathrm{C}$ NMR chemical shifts are observed. According to Manke et al. [36] the ${ }^{13} \mathrm{C}$ NMR resonances of the pyrrole carbon atoms $\mathrm{C}^{9,9^{\prime}}$ and $\mathrm{C}^{10,10^{\prime}}$ are not observable.

\section{Synthesis of $\mathbf{3}$}

To a suspension of $1(1.00 \mathrm{~g}, 1.26 \mathrm{mmol})$ in dichloromethane $(140 \mathrm{~mL})$, dimethylformamide $(1 \mathrm{~mL}, 12.9 \mathrm{mmol})$ was added. This reaction mixture was cooled to $0{ }^{\circ} \mathrm{C}$ and oxalyl chloride (3.20 mL, $37.31 \mathrm{mmol}$ ) was added dropwise (within $20 \mathrm{~min}$ ) under continuous stirring. The mixture was stirred at $0{ }^{\circ} \mathrm{C}$ for further $30 \mathrm{~min}$ followed by refluxing for $3 \mathrm{~h}$. After all volatiles were removed under reduced pressure the obtained crude product was dissolved in dichloromethane $(30 \mathrm{~mL})$, and a mixture of diisopropylamine (11.52 g, $0.114 \mathrm{~mol}, 16 \mathrm{~mL})$ and triethylamine ( $1 \mathrm{~mL}, 7.17 \mathrm{mmol}$ ) was added dropwise at ambient temperature. The reaction mixture was refluxed for $24 \mathrm{~h}$. After cooling to ambient temperature, all volatiles were removed under reduced pressure, and hot distilled water $(100 \mathrm{~mL})$ was added to the crude product under continuous stirring for $30 \mathrm{~min}$. The purple precipitate formed was filtered off, washed with hot distilled water $(5 \times 20 \mathrm{~mL})$ and dried at $110^{\circ} \mathrm{C}$. Yield: $1.21 \mathrm{~g}$ (85\% based on 1). Anal. calcd for $\mathrm{C}_{72} \mathrm{H}_{82} \mathrm{~N}_{8} \mathrm{O}_{4}$ (1123.47): $\mathrm{C}$, 76.97; H, 7.36; N, 9.97; found: C, 76.8; H, 7.2; N 9.9. ${ }^{1} \mathrm{H}$ NMR $\left(\mathrm{CDCl}_{3}\right) \delta-2.78\left(\mathrm{~s}, 2 \mathrm{H}, \mathrm{H}^{\mathrm{a}, \mathrm{a}^{\prime}}\right), 1.43 / 1.66(\mathrm{~s}($ broad $) / \mathrm{s}($ broad $)$,

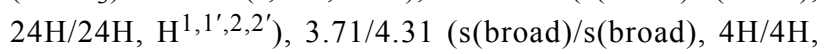
$\left.\mathrm{H}^{3,3^{\prime}}\right), 7.74\left(\mathrm{~d}, 8 \mathrm{H}, \mathrm{H}^{7,7^{\prime}}\right), 8.24\left(\mathrm{~d}, 8 \mathrm{H}, \mathrm{H}^{6,6^{\prime}}\right), 8.90(\mathrm{~s}, 8 \mathrm{H}$, $\left.\mathrm{H}^{11,11^{\prime}}\right) ;{ }^{13} \mathrm{C}\left\{{ }^{1} \mathrm{H}\right\} \operatorname{NMR}\left(\mathrm{CDCl}_{3}\right) \delta 21.24\left(\mathrm{C}^{1,1^{\prime}, 2,2^{\prime}}\right), 119.8\left(\mathrm{C}^{9}\right)$, $124.6\left(\mathrm{C}^{7,7^{\prime}}\right), 134.8\left(\mathrm{C}^{8}\right), 138.6\left(\mathrm{C}^{6,6^{\prime}}\right), 142.8\left(\mathrm{C}^{5}\right), 171.3\left(\mathrm{C}^{4}\right)$; HRMS (ESI-TOF, positive mode, $\mathrm{MeCN} / \mathrm{CH}_{2} \mathrm{Cl}_{2}$ ): $\mathrm{m} / \mathrm{z}$ $1123.6520[3+\mathrm{H}]^{+}, 1145.6319[3+\mathrm{Na}]^{+}$; calcd for $\mathrm{C}_{72} \mathrm{H}_{83} \mathrm{~N}_{8} \mathrm{O}_{4} / \mathrm{C}_{72} \mathrm{H}_{82} \mathrm{NaN}_{8} \mathrm{O}_{4}([3+\mathrm{H}] /[3+\mathrm{Na}])=1123.6532 /$ 1145.6351; IR (KBr, cm $\left.{ }^{-1}\right)$ v: $3317(\mathrm{w}, \mathrm{N}-\mathrm{H}) ; 2969 / 2932 / 2874$ $(\mathrm{m} / \mathrm{w} / \mathrm{w}, \mathrm{C}-\mathrm{H}) ; 1630 / 1608(\mathrm{~s}, \mathrm{C}=\mathrm{O}) ; \mathrm{UV}-\mathrm{vis}\left(\mathrm{CHCl}_{3}\right) \lambda_{\text {abs }}[\mathrm{nm}]$ (log $\varepsilon): 400$ (4.80), 420 (5.49), 482 (3.74), 517 (4.17), 552 (3.91), 591 (3.74), 648 (3.58). Supporting Information File 1 gives the IR, ${ }^{1} \mathrm{H} \mathrm{NMR},{ }^{13} \mathrm{C}\left\{{ }^{1} \mathrm{H}\right\} \mathrm{NMR}, \mathrm{UV}-$ vis and ESIMS spectra of $\mathbf{3}$.

Comments: The ${ }^{1} \mathrm{H}$ NMR resonances of the $\mathrm{N}(\mathrm{iPr})_{2}$ groups are all broadened. The hydrogen atoms $\mathrm{H}^{1,1^{\prime}, 2,2^{\prime}}$ are regarded to correspond to the two broad singlets at 1.39 and $1.69 \mathrm{ppm}$. The hydrogen atoms $\mathrm{H}^{3,3^{\prime}}$ are regarded to correspond to the two singlets at 3.71 and $4.31 \mathrm{ppm}$. Both assignments could, however, not be verified by additional 2D NMR experiments $\left({ }^{1} \mathrm{H},{ }^{1} \mathrm{H}-\right.$ COSY, ${ }^{1} \mathrm{H},{ }^{13} \mathrm{C}$-HSQCETGP and HMBCGP) because of too broad NMR resonances and/or the comparatively poor solubility. According to Jones and Wilkins [35] for the $-\mathrm{NMe}_{2}$ groups two ${ }^{13} \mathrm{C}$ NMR chemical shifts are observed. According to Manke et al. [36] the ${ }^{13} \mathrm{C}$ NMR resonances of the pyrrole carbon atoms $\mathrm{C}^{9,9^{\prime}}$ and $\mathrm{C}^{10,10^{\prime}}$ are not observable.

\section{General procedure for the synthesis of $\mathbf{2 a - d}$ and $\mathbf{3 a}-\mathbf{d}$}

Unless stated otherwise, the following procedure was used: To a solution of $2(0.200 \mathrm{~g}, 0.222 \mathrm{mmol})$ for $\mathbf{2 a}-\mathbf{d}$, or $\mathbf{3}$ $(0.200 \mathrm{~g}, 0.178 \mathrm{mmol})$ for $\mathbf{3 a}-\mathbf{d}$ in dimethylformamide $(25 \mathrm{~mL})$, a solution of the $\mathrm{MCl}_{2}$ salt (3 equiv) in dimethylformamide $(5 \mathrm{~mL}$ ) was added dropwise (within $5 \mathrm{~min}$ ) at ambient temperature. The reaction temperature was raised to $140{ }^{\circ} \mathrm{C}$ for $6 \mathrm{~h}$. After cooling the reaction mixture to ambient temperature, chloroform $(50 \mathrm{~mL})$ was added and the combined organic 
phases were washed with water $(3 \times 40 \mathrm{~mL})$ and brine $(3 \times 40 \mathrm{~mL})$ to remove the excess of the $\mathrm{MCl}_{2}$ salt. The organic phase was dried over magnesium sulfate, and all volatiles were removed in vacuo to afford solids of the corresponding metalloporphyrins, which were dried additionally in vacuo for $12 \mathrm{~h}$. Afterward, the corresponding solids were dissolved in $\mathrm{CHCl}_{3}$ and precipitated with $n$-hexane. That procedure is referred to in the following as "re-precipitation".

\section{Data for 2a}

2 (0.200 g, $0.222 \mathrm{mmol}), \mathrm{ZnCl}_{2}(0.0909 \mathrm{~g}, 0.667 \mathrm{mmol})$. Yield: $0.156 \mathrm{~g}$ (73\% based on 2); purple solid. Anal. calcd for $\mathrm{C}_{56} \mathrm{H}_{48} \mathrm{~N}_{8} \mathrm{O}_{4} \mathrm{Zn}$ (962.44): C, 69.88; H, 5.03; N, 11.64; found: $\mathrm{C}$, 69.5; H, 5.0; N, 11.5; ${ }^{1} \mathrm{H} \mathrm{NMR}\left(\mathrm{CDCl}_{3}\right) \delta 3.16 / 3.26(\mathrm{~s} / \mathrm{s}, 12 \mathrm{H} /$ $\left.12 \mathrm{H}, \mathrm{H}^{1,2}\right), 7.68\left(\mathrm{~d}, 8 \mathrm{H}, \mathrm{H}^{6,6^{\prime}}\right), 8.23\left(\mathrm{~d}, 8 \mathrm{H}, \mathrm{H}^{5,5^{\prime}}\right), 8.93(\mathrm{~s}, 8 \mathrm{H}$, $\mathrm{H}^{10,10^{\prime}}$ ); HRMS (ESI-TOF, positive mode, $\mathrm{MeCN} / \mathrm{CH}_{2} \mathrm{Cl}_{2}$ ): $\mathrm{m} / \mathrm{z}$ 960.3058/961.3149 [2a $]^{+} /[\mathbf{2 a}+\mathrm{H}]^{+}, 983.2908[\mathbf{2 a}+\mathrm{Na}]^{+}$, $999.2716[\mathbf{2 a}+\mathrm{K}]^{+}$; calcd for $\mathrm{C}_{56} \mathrm{H}_{48} \mathrm{~N}_{8} \mathrm{O}_{4} \mathrm{Zn} / \mathrm{C}_{56} \mathrm{H}_{49} \mathrm{~N}_{8} \mathrm{O}_{4} \mathrm{Zn}$, $\mathrm{C}_{56} \mathrm{H}_{48} \mathrm{NaN}_{8} \mathrm{O}_{4} \mathrm{Zn}, \mathrm{C}_{56} \mathrm{H}_{48} \mathrm{KN}_{8} \mathrm{O}_{4} \mathrm{Zn}([\mathbf{2 a}] /[\mathbf{2 a}+\mathrm{H}],[\mathbf{2 a}+\mathrm{Na}]$, $[2 \mathbf{a}+\mathrm{K}]=960.3058 / 961.3163,983.2982,999.2722$; IR $(\mathrm{KBr}$, $\left.\mathrm{cm}^{-1}\right)$ v: $2929(\mathrm{w}, \mathrm{C}-\mathrm{H}) ; 1612(\mathrm{~s}, \mathrm{C}=\mathrm{O})$; UV-vis $\left(\mathrm{CHCl}_{3}\right) \lambda_{\mathrm{abs}}$ [nm] (log $\varepsilon)$ : 403 (4.55), 426 (5.55), 555 (4.19), 596 (3.73). Supporting Information File 1 gives the IR, ${ }^{1} \mathrm{H}$ NMR, UV-vis and ESIMS spectra of $\mathbf{2 a}$.

Comments: No re-precipitation needed. Due to the poor solubility of 2 a a ${ }^{13} \mathrm{C}$ NMR spectrum could not be recorded. The ESIMS spectra of 2a reveals as basis peak 988.3599. The origin of this peak remains unclear and may likely correspond to a fragmentation/recombination process under ESIMS measurement conditions.

\section{Data for $\mathbf{2 b}$}

2 (0.200 g, $0.222 \mathrm{mmol}), \mathrm{CuCl}_{2}(0.0897 \mathrm{~g}, 0.667 \mathrm{mmol})$. Yield: $0.130 \mathrm{~g}$ (61\% based on 2); wine red solid. Anal. calcd for $\mathrm{C}_{56} \mathrm{H}_{48} \mathrm{CuN}_{8} \mathrm{O}_{4}$ (960.58): C, 70.02; H, 5.04; N, 11.76; found: C, 69.9; H, 5.0; N, 11.6; HRMS (ESI-TOF, positive mode, $\mathrm{MeCN} / \mathrm{CH}_{2} \mathrm{Cl}_{2}$ ): $m / z 960.3254$ [2b] ${ }^{+}$; calcd for $\mathrm{C}_{56} \mathrm{H}_{48} \mathrm{CuN}_{8} \mathrm{O}_{4}$ [2b] 960.3128; IR $\left(\mathrm{KBr}, \mathrm{cm}^{-1}\right)$ v: 2928/2932 (w/w, C-H); 1622 $(\mathrm{C}=\mathrm{O})$; UV-vis $\left(\mathrm{CHCl}_{3}\right) \lambda_{\text {abs }}[\mathrm{nm}](\log \varepsilon): 396$ (4.44), 419 (5.65), 543 (4.28), 578 (3.39). Supporting Information File 1 gives the IR, UV-vis and ESIMS spectra of $\mathbf{2} \mathbf{b}$.

Comments: No re-precipitation needed.

\section{Data for 2c}

2 (0.200 g, $0.222 \mathrm{mmol}), \mathrm{NiCl}_{2}(0.0865 \mathrm{~g}, 0.667 \mathrm{mmol})$. Yield: $0.149 \mathrm{~g}(70 \%$ based on 2); brown solid. Anal. calcd for $\mathrm{C}_{56} \mathrm{H}_{48} \mathrm{~N}_{8} \mathrm{NiO}_{4}$ (955.72): C, 70.38; H, 5.06; N, 11.72; found: $\mathrm{C}$, $70.1 ; \mathrm{H}, 5.0 ; \mathrm{N}, 11.6 ;{ }^{1} \mathrm{H} \mathrm{NMR}\left(\mathrm{CDCl}_{3}\right) \delta 3.27\left(\mathrm{~s}, 24 \mathrm{H}, \mathrm{H}^{1,2}\right)$, $7.76\left(\mathrm{~d}, 8 \mathrm{H}, \mathrm{H}^{6,6^{\prime}}\right), 8.05\left(\mathrm{~d}, 8 \mathrm{H}, \mathrm{H}^{5,5^{\prime}}\right), 8.76\left(\mathrm{~s}, 8 \mathrm{H}, \mathrm{H}^{10,10^{\prime}}\right)$;
${ }^{13} \mathrm{C}\left\{{ }^{1} \mathrm{H}\right\}$ NMR $\left(\mathrm{CDCl}_{3}\right) \delta 24.41\left(\mathrm{C}^{1}\right), 33.87\left(\mathrm{C}^{2}\right), 118.47\left(\mathrm{C}^{8}\right)$, $125.96\left(\mathrm{C}^{6,6^{\prime}}\right), 132.46\left(\mathrm{C}^{10,10^{\prime}}\right), 133.73\left(\mathrm{C}^{7}\right), 135.96\left(\mathrm{C}^{5,5^{\prime}}\right)$, $142.20\left(\mathrm{C}^{9,9^{\prime}}\right), 142.67\left(\mathrm{C}^{4}\right), 171.69\left(\mathrm{C}^{3}\right)$; HRMS (ESI-TOF, positive mode, $\left.\mathrm{MeCN} / \mathrm{CH}_{2} \mathrm{Cl}_{2}\right): m / z 955.3153[2 \mathrm{c}+\mathrm{H}]^{+}$; calcd for $\mathrm{C}_{56} \mathrm{H}_{49} \mathrm{~N}_{8} \mathrm{NiO}_{4}[2 \mathrm{c}+\mathrm{H}]=955.3225$; IR $\left(\mathrm{KBr}, \mathrm{cm}^{-1}\right) v$ : 2924/2854 (w/w, C-H); 1626 (s, C=O); UV-vis $\left(\mathrm{CHCl}_{3}\right) \lambda_{\text {abs }}$ [nm] $(\log \varepsilon): 416$ (5.30), 528 (4.17). Supporting Information File 1 gives the IR, ${ }^{1} \mathrm{H}$ NMR, ${ }^{13} \mathrm{C}\left\{{ }^{1} \mathrm{H}\right\} \mathrm{NMR}, \mathrm{UV}-\mathrm{vis}$ and ESIMS spectra of $\mathbf{2 c}$.

Comments: No re-precipitation needed. Due to a better solubility of $\mathbf{2 c}$ as compared to $\mathbf{2 a},{ }^{13} \mathrm{C}$ NMR spectra could be recorded. In contrast to comments made for $\mathbf{2}$, all chemically different carbon atoms were observable, although for the $-\mathrm{NMe}_{2}$ groups of $2 \mathbf{c}$ two ${ }^{13} \mathrm{C}$ NMR resonances were observed as reported for 2 .

\section{Data for $\mathbf{2 d}$}

2 (0.200 g, $0.222 \mathrm{mmol}), \mathrm{CoCl}_{2}(0.0867 \mathrm{~g}, 0.667 \mathrm{mmol})$. Yield: $0.155 \mathrm{~g}(73 \%$, based on 2); wine red solid. Anal. calcd for $\mathrm{C}_{56} \mathrm{H}_{48} \mathrm{CoN}_{8} \mathrm{O}_{4}$ (955.96): C, 70.36; H, 5.05; N, 11.72; found: C, 70.1; H, 5.0;N, 11.7; HRMS (ESI-TOF, positive mode, $\mathrm{MeCN} / \mathrm{CH}_{2} \mathrm{Cl}_{2}$ ): $m / z$ 955.3125 [2d] ${ }^{+}$; calcd for $\mathrm{C}_{56} \mathrm{H}_{48} \mathrm{~N}_{8} \mathrm{CoO}_{4}$ [2d] = 955.3125; IR $\left(\mathrm{KBr}, \mathrm{cm}^{-1}\right)$ v: 2927/2852 (w/w, C-H); 1625 (s, C=O); UV-vis $\left(\mathrm{CHCl}_{3}\right) \lambda_{\mathrm{abs}}[\mathrm{nm}](\log \varepsilon): 412$ (5.24), 442 (4.44), 530 (4.03). Supporting Information File 1 gives the IR, UV-vis and ESIMS spectra of $\mathbf{2 d}$.

Comments: Re-precipitation needed.

\section{Data for 3a}

3 (0.200 g, $0.178 \mathrm{mmol}), \mathrm{ZnCl}_{2}$ (0.0728 g, $\left.0.534 \mathrm{mmol}\right)$. Yield: $0.192 \mathrm{~g}$ (91\% based on 3); purple solid. Anal. calcd for $\mathrm{C}_{72} \mathrm{H}_{80} \mathrm{~N}_{8} \mathrm{O}_{4} \mathrm{Zn}$ (1186.87): C, 72.86; H, 6.79; N, 9.44, found: $\mathrm{C}$, 72.1; H, 6.6; N, 9.23; ${ }^{1} \mathrm{HNMR}\left(\mathrm{CDCl}_{3}\right) \delta 1.45 / 1.59$ (s(broad)/

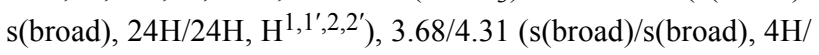
$\left.4 \mathrm{H}, \mathrm{H}^{3,3^{\prime}}\right), 7.65\left(\mathrm{~d}, 8 \mathrm{H}, \mathrm{H}^{7,7^{\prime}}\right), 8.22\left(\mathrm{~d}, 8 \mathrm{H}, \mathrm{H}^{6,6^{\prime}}\right), 8.98(\mathrm{~s}, 8 \mathrm{H}$, $\left.\mathrm{H}^{11,11^{\prime}}\right) ;{ }^{13} \mathrm{C}\left\{{ }^{1} \mathrm{H}\right\} \mathrm{NMR}\left(\mathrm{CDCl}_{3}\right) \delta 20.85\left(\mathrm{C}^{1,1^{\prime}, 2,2^{\prime}}\right), 120.46$ $\left(\mathrm{C}^{9}\right), 124.11\left(\mathrm{C}^{7,7^{\prime}}\right), 132.08\left(\mathrm{C}^{11,11^{\prime}}\right), 134.48\left(\mathrm{C}^{8}\right), 137.85$ $\left(\mathrm{C}^{6,6^{\prime}}\right), 143.34\left(\mathrm{C}^{5}\right), 150.08\left(\mathrm{C}^{10,10^{\prime}}\right), 171.08\left(\mathrm{C}^{4}\right)$; HRMS (ESITOF, positive mode, $\left.\mathrm{MeCN} / \mathrm{CH}_{2} \mathrm{Cl}_{2}\right): m / z 1185.5632$ $[3 \mathbf{a}+\mathrm{H}]^{+}, 1207.5471[3 \mathbf{a}+\mathrm{Na}]^{+}$; calcd for $\mathrm{C}_{72} \mathrm{H}_{81} \mathrm{ZnN}_{8} \mathrm{O}_{4} /$ $\mathrm{C}_{72} \mathrm{H}_{80} \mathrm{NaZnN}_{8} \mathrm{O}_{4}([\mathbf{3 a}+\mathbf{H}] /[\mathbf{3 a}+\mathrm{Na}])=1185.5667 /$ 1207.5486; IR (KBr, cm ${ }^{-1}$ ) v: 2969/2928/2869 (m/w/w, C-H); 1632 (s, C=O); UV-vis $\left(\mathrm{CHCl}_{3}\right) \lambda_{\text {abs }}[\mathrm{nm}](\log \varepsilon): 404$ (4.33), 426 (5.29), 556 (3.93), 597 (3.53). Supporting Information File 1 gives the IR, ${ }^{1} \mathrm{H}$ NMR, ${ }^{13} \mathrm{C}\left\{{ }^{1} \mathrm{H}\right\} \mathrm{NMR}, \mathrm{UV}$-vis and ESIMS spectra of $\mathbf{3 a}$.

Comments: Re-precipitation needed. Because 3a is better soluble than $2 \mathrm{a},{ }^{13} \mathrm{C}$ NMR spectra could be recorded. In con- 
trast to comments made for $\mathbf{3}$, all chemically different carbon atoms beside $\mathrm{C}^{3,3^{\prime}}$ (belonging to the $-\mathrm{N}(\mathrm{iPr})_{2}$ groups) were observable. On the other hand, as discussed for $\mathbf{3}$ broad singlets in the ${ }^{1} \mathrm{H}$ NMR spectra are regarded to correspond to the hydro-

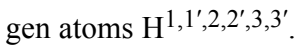

\section{Data for $\mathbf{3 b}$}

3 (0.200 g, $0.178 \mathrm{mmol}), \mathrm{CuCl}_{2}(0.0718,0.534 \mathrm{mmol})$. Yield: $0.124 \mathrm{~g}$ ( $59 \%$ based on 3 ); wine red solid. Anal. calcd for $\mathrm{C}_{72} \mathrm{H}_{80} \mathrm{CuN}_{8} \mathrm{O}_{4}(1185.0)$ : C, 72.98; H, 6.80; N, 9.46; found: $\mathrm{C}$, 72.5; H, 6.7;N, 9.4; HRMS (ESI-TOF, positive mode, MeCN/ $\left.\mathrm{CH}_{2} \mathrm{Cl}_{2}\right): m / z 1184.5665[3 \mathbf{b}]^{+}$; calcd for $\mathrm{C}_{72} \mathrm{H}_{80} \mathrm{CuN}_{8} \mathrm{O}_{4}[3 \mathbf{b}]$ $=1184.5671$; IR $\left(\mathrm{KBr}, \mathrm{cm}^{-1}\right)$ v: 2966/2928/2869 (m/w/w, $\mathrm{C}-\mathrm{H}) ; 1632(\mathrm{~s}, \mathrm{C}=\mathrm{O}) ; \mathrm{UV}-\mathrm{vis}\left(\mathrm{CHCl}_{3}\right) \lambda_{\mathrm{abs}}[\mathrm{nm}](\log \varepsilon): 397$ (4.58), 419 (5.72), 542 (4.36), 579 (3.46). Supporting Information File 1 gives the IR, UV-vis and ESIMS spectra of $\mathbf{3 b}$.

Comments: No re-precipitation needed.

\section{Data for 3c}

3 (0.200 g, $0.178 \mathrm{mmol}), \mathrm{NiCl}_{2}(0.0692 \mathrm{~g}, 0.534 \mathrm{mmol})$. Yield: $0.126 \mathrm{~g}(60 \%$, based on 3$)$; brown solid. Anal. calcd for $\mathrm{C}_{72} \mathrm{H}_{80} \mathrm{~N}_{8} \mathrm{NiO}_{4}(1180.15)$ : C, 73.28; H, 6.83; N, 9.49; found: $\mathrm{C}$, 72.9; H, 6.8; N, 9.4; ${ }^{1} \mathrm{H}$ NMR $\left(\mathrm{CDCl}_{3}\right) \delta 1.40 / 1.62$ (s(broad)/

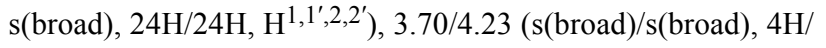
$\left.4 \mathrm{H}, \mathrm{H}^{3,3^{\prime}}\right), 7.66\left(\mathrm{~d}, 8 \mathrm{H}, \mathrm{H}^{7,7^{\prime}}\right), 8.03\left(\mathrm{~d}, 8 \mathrm{H}, \mathrm{H}^{6,6^{\prime}}\right), 8.79(\mathrm{~s}, 8 \mathrm{H}$, $\left.\mathrm{H}^{11,11^{\prime}}\right) ;{ }^{13} \mathrm{C}\left\{{ }^{1} \mathrm{H}\right\} \operatorname{NMR}\left(\mathrm{CDCl}_{3}\right) \delta 21.00\left(\mathrm{C}^{1,1^{\prime}, 2,2^{\prime}}\right), 118.55$ $\left(\mathrm{C}^{9}\right), 124.65\left(\mathrm{C}^{7,7^{\prime}}\right), 132.46\left(\mathrm{C}^{11,11^{\prime}}\right), 133.96\left(\mathrm{C}^{8}\right), 138.57$ $\left(\mathrm{C}^{6,6^{\prime}}\right), 141.34\left(\mathrm{C}^{5}\right), 142.76\left(\mathrm{C}^{10,10^{\prime}}\right), 171.07\left(\mathrm{C}^{4}\right)$; HRMS (ESI-TOF, positive mode, $\mathrm{MeCN} / \mathrm{CH}_{2} \mathrm{Cl}_{2}$ ): $\mathrm{m} / z 1179.5713$ $[3 \mathbf{c}+\mathrm{H}]^{+}, 1201.5520[3 \mathbf{c}+\mathrm{Na}]^{+}$; calcd for $\mathrm{C}_{72} \mathrm{H}_{81} \mathrm{NiN}_{8} \mathrm{O}_{4} /$ $\mathrm{C}_{72} \mathrm{H}_{80} \mathrm{NaNiN}_{8} \mathrm{O}_{4}([\mathbf{3 c}+\mathrm{H}] /[\mathbf{3 c}+\mathrm{Na}])=1179.5729 /$ 1201.5548; IR (KBr, cm ${ }^{-1}$ ) v: 2969/2928/2875 (w/w/w, C-H); 1630 (s, C=O); UV-vis $\left(\mathrm{CHCl}_{3}\right) \lambda_{\mathrm{abs}}[\mathrm{nm}](\log \varepsilon): 417$ (5.32), 530 (4.23). Supporting Information File 1 gives the IR, ${ }^{1} \mathrm{H}$ NMR, ${ }^{13} \mathrm{C}\left\{{ }^{1} \mathrm{H}\right\} \mathrm{NMR}, \mathrm{UV}$-vis and ESIMS spectra of 3c.

Comments: No re-precipitation needed. As discussed for 3a (above), analogous observations were made for $\mathbf{3 c}$.

\section{Data for 3d}

3 (0.200 g, $0.178 \mathrm{mmol}), \mathrm{CoCl}_{2}(0.0693 \mathrm{~g}, 0.534 \mathrm{mmol})$. Yield: $0.164 \mathrm{~g}(78 \%$, based on 3); wine red solid. Anal. calcd for $\mathrm{C}_{72} \mathrm{H}_{80} \mathrm{CoN}_{8} \mathrm{O}_{4}$ (1180.39): C, 73.26; H, 6.83; N, 9.49; found: C, 72.8; H, 6.7; N, 9.3; HRMS (ESI-TOF, positive mode,

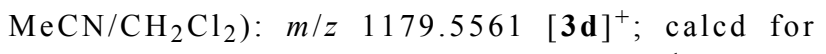
$\mathrm{C}_{72} \mathrm{H}_{80} \mathrm{CuN}_{8} \mathrm{O}_{4}[\mathbf{3 d}]=1179.5629$; IR $\left(\mathrm{KBr}, \mathrm{cm}^{-1}\right) v: 2963 /$ 2931/2869 (m/w/w, C-H); 1629 (s, C=O); UV-vis $\left(\mathrm{CHCl}_{3}\right) \lambda_{\text {abs }}$ [nm] $(\log \varepsilon): 412$ (5.47), 529 (4.25). Supporting Information File 1 gives the IR, UV-vis and ESIMS spectra of $\mathbf{3 d}$.
Comments: Re-precipitation needed.

\section{Supporting Information}

Supporting Information File 1 features ${ }^{1} \mathrm{H}$ and ${ }^{13} \mathrm{C}\left\{{ }^{1} \mathrm{H}\right\}$ NMR spectra of 2, 2a, 2c, 3, 3a and 3c, ESIMS, UV-vis and IR spectra (ATR-IR and KBr) of 2, 2a-2d, $\mathbf{3}$ and $\mathbf{3 a}-\mathbf{3 d}$, and IR spectra of $\mathbf{3 b}$ and $\mathbf{3 d}$ before and after OMBD together with optical photographs of the materials.

\section{Supporting Information File 1}

Additional experimental data.

[http://www.beilstein-journals.org/bjnano/content/ supplementary/2190-4286-8-121-S1.pdf]

\section{Acknowledgements}

This work has been supported by the Deutsche Forschungsgemeinschaft through project FOR 1154 "Towards Molecular Spintronics". We thank Janine Freytag, Brigitte Kempe and Dipl.-Chem. Natalia Rüffer for EA, ESIMS and TG measurements.

\section{References}

1. Dolphin, D. The Porphyrins; Academic Press: New York, NY, USA, 1978.

2. Kadish, K. M.; Smith, K. M.; Guiard, R. The Porphyrins Handbook; Academic Press (Elsevier Science): Amsterdam, Netherlands, 2000.

3. Vicente, M. G. H.; Smith, K. M. Curr. Org. Synth. 2014, 11, 3-28. doi:10.2174/15701794113106660083

4. Birnbaum, T.; Hahn, T.; Martin, C.; Kortus, J.; Fronk, M.; Lungwitz, F.; Zahn, D. R. T.; Salvan, G. J. Phys.: Condens. Matter 2014, 26, 104201. doi:10.1088/0953-8984/26/10/104201

5. Wang, F. J.; Yang, C. G.; Vardeny, Z. V. Phys. Rev. B 2007, 75, 245324. doi:10.1103/PhysRevB.75.245324

6. Smykalla, L.; Shukrynau, P.; Mende, C.; Rüffer, T.; Lang, H.; Hietschold, M. Surf. Sci. 2014, 628, 92-97. doi:10.1016/j.susc.2014.05.015

7. Smykalla, L.; Shukrynau, P.; Mende, C.; Rüffer, T.; Lang, H.; Hietschold, M. Surf. Sci. 2014, 628, 132-140. doi:10.1016/j.susc.2014.06.001

8. Siles, P. F.; Bufon, C. C. B.; Grimm, D.; Jalil, A. R.; Mende, C.; Lungwitz, F.; Salvan, G.; Zahn, D. R. T.; Lang, H.; Schmidt, O. G. Org. Electron. 2014, 15, 1432-1439. doi:10.1016/j.orgel.2014.04.004

9. Lungwitz, F.; Mende, C.; Fronk, M.; Haidu, F.; Lang, H.; Salvan, G.; Zahn, D. R. T. Thin Solid Films 2014, 571, 377-383. doi:10.1016/j.tsf.2014.03.055

10. Granados-Oliveros, G.; Páez-Mozo, E. A.; Ortega, F. M.; Piccinato, M. T.; Silva, F. N.; Guedes, C. L. B.; Di Mauro, E.; da Costa, M. F.; Ota, A. T. J. Mol. Catal. A: Chem. 2011, 339, 79-85. doi:10.1016/j.molcata.2011.02.015

11. Wang, C.; Yang, G.-M.; Li, J.; Mele, G.; Słota, G.; Broda, M. A.; Duan, M.-Y.; Vasapollo, G.; Zhang, X.; Zhang, F.-X. Dyes Pigm. 2009, 80, 321-328. doi:10.1016/j.dyepig.2008.08.008 
12. Zheng, W.; Shan, N.; Yu, L.; Wang, X. Dyes Pigm. 2008, 77, 153-157. doi:10.1016/j.dyepig.2007.04.007

13. McGill, S.; Nesterov, V. N.; Gould, S. L. Acta Crystallogr., Sect. E 2013, 69, m471. doi:10.1107/S1600536813019338

14. Goldberg, I.; Krupitsky, H.; Stein, Z.; Hsiou, Y.; Strouse, C. E. Supramol. Chem. 1994, 4, 203-221. doi:10.1080/10610279408029473

15. Isthaiwi, Z.; Rüffer, T.; Klaib, S.; Buschbeck, R.; Walfort, B.; Lang, H. Dalton Trans. 2014, 43, 7868-7888. doi:10.1039/C3DT53535E

16. Chen, W.; El-Khouly, M. E.; Fukuzumi, S. Inorg. Chem. 2011, 50, 671-678. doi:10.1021/ic102208y

17. Shirakawa, M.; Kawano, S. I.; Fujita, N.; Sada, K.; Shinkai, S. J. Org. Chem. 2003, 68, 5037-5044. doi:10.1021/jo0341822

18. Gradl, S. N.; Felix, J. P.; Isacoff, E. Y.; Garcia, M. L.; Trauner, D. J. Am. Chem. Soc. 2003, 125, 12668-12669. doi:10.1021/ja036155z

19. Buchler, J. W. Synthesis and Properties of Metalloporphyrins. In The Porphyrins; Dolphin, D., Ed.; Academic Press: New York, NY, USA, 1978; Vol. 1, pp 389-483. doi:10.1016/B978-0-12-220101-1.50017-2

20. Rüffer, T.; Nurpeisova, D.; Jakupova, Z.; Tashenov, A.; Uhlig, N.; Khalladi, A.; Mertens, L.; Gonser, A.; Mehring, M.; Lang, H. Z. Naturforsch., B 2017, submitted.

21. White, W. I.; Bachmann, R. C.; Burnham, B. F. Chromatography of porphyrins and metalloporphyrins. In The Porphyrins; Dolphin, D., Ed.; Academic Press: New York, USA, 1978; Vol. I, pp 553-580. doi:10.1016/b978-0-12-220101-1.50019-6

22. Budzikiewicz, H. Mass spectra of porphyrins and related compounds. In The Porphyrins; Dolphin, D., Ed.; Academic Press: New York, NY, USA, 1978; Vol. 3, pp 395-461. doi:10.1016/B978-0-12-220103-5.50016-7

23. Cole, R. B. Electrospray ionization mass spectrometry: fundamentals, instrumentation, and applications; John Wiley \& Sons, Inc.: New York, NY, USA, 1997

24. Keller, B. O.; Sui, J.; Young, A. B.; Whittal, R. M. Anal. Chim. Acta 2008, 627, 71-81. doi:10.1016/j.aca.2008.04.043

25. Alben, J. O. Infrared Spectroscopy of Porphyrins. In The Porphyrins; Dolphin, D., Ed.; Academic Press: New York, NY, USA, 1978; Vol. 3, pp 323-345. doi:10.1016/B978-0-12-220103-5.50014-3

26. Steger, E.; Adler, B.; Brunn, J.; Doerffel, K.; Höbold, W.; Mehlhorn, A.; Müller, E.; Treibmann, D. Lehrwerkreihe Chemie: StrukturaufklärungSpektroskopie und Röntgenbeugung, Arbeitsbuch; VEB Deutscher Verlag für Grundstoffindustrie: Leipzig, GDR, 1973.

27. Becker, H. G. O.; Domschke, G.; Fanghänel, E.; Fischer, M.; Gewald, K.; Mayer, R.; Pavel, D.; Schmidt, H.; Schwetlick, K.; Berger, W.; Faust, J.; Gentz, F.; Gluch, R.; Müller, K.; Schollberg, K.; Seiler, E.; Zeppenfeld, G.; Fabian, J.; Frach, K.; Lohs, K.; Kläsz, V. Organikum; Deutscher Verlag der Wissenschaften: Berlin, GDR, 1976.

28. McKeown, N. B. Phthalocyanine Materials Synthesis, Structure and Function; Cambridge University Press: UK, 1998; pp 88-93.

29. Gouterman, M. Optical Spectra and Electronic Structure of Porphyrins and Related Rings. In The Porphyrins; Dolphin, D., Ed.; Academic Press: New York, NY, USA, 1978; Vol. 3, pp 2-24. doi:10.1016/B978-0-12-220103-5.50008-8

30. Gouterman, M. J. Mol. Spectrosc. 1961, 6, 138-163. doi:10.1016/0022-2852(61)90236-3

31. Abdulmalic, M. A.; Fronk, M.; Bräuer, B.; Zahn, D. R. T.; Salvan, G.; Meva, F. E.; Rüffer, T. J. Magn. Magn. Mater. 2016, 419, 17-28. doi:10.1016/j.jmmm.2016.06.002

32. Perin, D. D.; Armarego, W. L. F. Purification of Laboratory Chemicals, 3rd ed.; Pergamon: New York, NY, USA, 1988.

33. Adler, A. D.; Longo, F. R.; Finarelli, J. D.; Goldmacher, J.; Assour, J.; Korsakoff, L. A. J. Org. Chem. 1967, 32, 476. doi:10.1021/jo01288a053
34. Freeman, J. H.; Smith, M. L. J. Inorg. Nucl. Chem. 1958, 7, 224-227. doi:10.1016/0022-1902(58)80073-1

35. Jones, R. G.; Wilkins, J. M. Org. Magn. Reson. 1978, 11, $20-26$. doi:10.1002/mrc.1270110106

36. Manke, A.-M.; Geisel, K.; Fetzer, A.; Kurz, P. Phys. Chem. Chem. Phys. 2014, 16, 12029-12042. doi:10.1039/c3cp55023k

\section{License and Terms}

This is an Open Access article under the terms of the Creative Commons Attribution License (http://creativecommons.org/licenses/by/4.0), which permits unrestricted use, distribution, and reproduction in any medium, provided the original work is properly cited.

The license is subject to the Beilstein Journal of Nanotechnology terms and conditions: (http://www.beilstein-journals.org/bjnano)

The definitive version of this article is the electronic one which can be found at: doi:10.3762/bjnano.8.121 